\title{
Luminescent acetylthiol derivative tripodal osmium(II) and iridium(III) complexes: Spectroscopy in solution and on surfaces
}

\section{Citation}

Ramachandra, Srinidhi, Federico Polo, Fabio Edafe, Klaus C. Schuermann, Christian A. Nijhuis, Peter Belser, William F. Reus, George M. Whitesides, and Luisa De Cola. 2011. "Luminescent Acetylthiol Derivative Tripodal osmium(II) and iridium(III) Complexes: Spectroscopy in Solution and on Surfaces." Pure and Applied Chemistry 83, no. 4: 779-799.

\section{Published Version}

doi:10.1351/PAC-CON-10-11-07

\section{Permanent link}

http://nrs.harvard.edu/urn-3:HUL.InstRepos:12967686

\section{Terms of Use}

This article was downloaded from Harvard University's DASH repository, and is made available under the terms and conditions applicable to Other Posted Material, as set forth at http:// nrs.harvard.edu/urn-3:HUL.InstRepos:dash.current.terms-of-use\#LAA

\section{Share Your Story}

The Harvard community has made this article openly available.

Please share how this access benefits you. Submit a story.

Accessibility 
Pure Appl. Chem., Vol. 83, No. 4, pp. 779-799, 2011.

doi:10.1351/PAC-CON-10-11-07

(C) 2011 IUPAC, Publication date (Web): 18 March 2011

\title{
Luminescent acetylthiol derivative tripodal osmium(II) and iridium(III) complexes: Spectroscopy in solution and on surfaces*
}

\author{
Srinidhi Ramachandra ${ }^{1}$, Federico Polo ${ }^{2}$, Fabio Edafe ${ }^{3}$, \\ Klaus C. Schuermann², Christian A. Nijhuis ${ }^{4}$, Peter Belser ${ }^{3, \ddagger}$, \\ William F. Reus ${ }^{4}$, George M. Whitesides ${ }^{4}$, and Luisa De Cola ${ }^{1,2, \neq}$ \\ ${ }^{1}$ Laboratory of Supramolecular Chemistry and Technology, University of Twente, \\ P.O. Box 217, 7500 AE Enschede, The Netherlands; ${ }^{2}$ Westfälische Wilhelms- \\ Universität Münster, Physikalisches Institut, Mendelstraße 7, 48149 Münster, \\ Germany; ${ }^{3}$ Department of Chemistry, University of Fribourg, Chemin du Musée 9, \\ 1700 Fribourg, Switzerland; ${ }^{4}$ Department of Chemistry and Chemical Biology, \\ Harvard University, 12 Oxford Street, Cambridge, MA 02138, USA
}

\begin{abstract}
Luminescent Os(II) and Ir(III) complexes containing a tripodal-type structure terminalized with three thiol derivatives are described. The tripod is introduced through derivatization, with a rigid spacer, of a phenanthroline ligand coordinated to the metal ion, and the entire structure possesses axial geometry. The geometry of the complexes combined with the three anchoring sites, the thiol groups, allows the complexes to adopt an almost perpendicular arrangement to the surfaces and the formation of a well-packed monolayer on Au substrates. The photophysical and electrochemical behavior of the complexes is studied in solution and on surfaces. Furthermore, a self-assembled monolayer (SAM) of Os(II) complexes on an ultraflat $\mathrm{Au}$ surface is used to fabricate a metal-molecule-metal junction with Au and In Ga eutectic as electrodes. The Os(II) SAM in the tunneling junction exhibits rectification behavior which is opposite in direction to that which we have previously shown for $\mathrm{Ru}$ (II) SAMs.
\end{abstract}

Keywords: iridium complexes; luminescence; osmium complexes; photophysics; self-assembled monolayers.

\section{INTRODUCTION}

In the past two decades, a lot of research was directed toward the field of molecular electronics driven by the idea of miniaturization [1-4]. Small structures can be obtained by a top-down approach or by a bottom-up strategy consisting in molecular self-assembly [5-7]. Monolayers of electroactive molecules on bulk metallic surfaces, in particular, Au and Pt have shown interesting behavior and some promising results [8-10]. The central key feature is to have electro/photoactive organic and organometallic fragments assembled onto these surfaces and study their charge conductivity [11-15] or eventually their electroluminescence in molecular junctions [16]. Different chemical functionality is required to assem-

\footnotetext{
*Paper based on a presentation made at the XXIII' ${ }^{\text {rd }}$ IUPAC Symposium on Photochemistry, Ferrara, Italy, 11-16 July 2010. Other presentations are published in this issue, pp. 733-930.

¥Corresponding authors: E-mail: decola@uni-muenster.de
} 
ble these molecules on the bulk surfaces through covalent and noncovalent interactions. The most extensively studied substrate for the self-assembled monolayers (SAMs) is Au, and the functional group that has the best affinity to the Au surface is the thiol group [17-20]. Traditionally, various organic molecules functionalized with thiols have been investigated for this purpose. However, recently there has been some interest toward employing organometallic complexes containing $\mathrm{Ru}$ [21-24] and Os [21,25-33] metal ions and ligands derivatized with thiols and amino groups for SAM formation. High stability coupled with very good photophysical and electrochemical behavior, as well as the possibility to have multielectron processes make them appealing candidates over conventional organic molecules. $\mathrm{Ru}$ (II) and Os(II) complexes possessing the above-mentioned anchoring groups are, however, not easy to synthesize. Furthermore, their octahedral geometry leads to substitution of the ligands, in the first coordination sphere, with aliphatic and aromatic groups, which adopt a tilt geometry when assembled on surfaces resulting in bad-quality monolayers and difficult control of the distance between the metal complexes and the substrate. In order to achieve well-ordered monolayers with these compounds, it is desirable to have rigid spacer groups between the metal coordination sphere and the metallic surface and to develop a strategy for the vertical substitution of the chelating ligands. Tridentate ligands such as terpyridine derivatives are good choices in term of geometry, but many of these metal complexes are not or only weakly luminescent with such ligands. Various rigid moieties containing thiol or amino functionality, substituted on different $N-N$ chelating ligands, have been employed by different groups [34-36]. From these results it is evident that multiple anchoring groups would lead to a better stability of the formed monolayers. Therefore, more recently, bipyridine derivatives containing tripodal-type ligands bearing anchoring groups at each leg of the tripod have been designed by a few research groups [34,37-39]. Following the same rationale we have designed rigid tripodal complexes of Ru, Os, and Ir with acetylthiol terminal groups. In an earlier report, we have described the synthesis and properties of a Ru tripodal complex with such rigid geometry [24]. In this contribution, we are reporting the synthesis, photophysical and electrochemical properties of structurally similar Os and Ir tripodal complexes. Further, we have looked at the conductivity of SAMs of the Os complex on Au surface as the bottom electrode and the alloy of gallium indium eutectic (EGaIn) as the top electrode. The electrochemical behavior of the SAM in the junction is reported.

\section{EXPERIMENTAL}

All reactions were carried out under an Ar atmosphere and with oven-dried glassware. Solvents were distilled from the appropriate drying agents. The Pd catalyst was purchased from Strem. All other reagents were purchased commercially from Fluka, Aldrich, and Acros and used without further purification unless otherwise noted. The synthesis of dichlorotetrakis[2-(2-pyridinyl)phenyl]diiridium(III) and the reference compound $\left[\mathrm{Os}(\mathrm{bpy})_{3}\right]\left(\mathrm{PF}_{6}\right)_{2}$ was reproduced following literature reports $[40,41]$.

Thin-layer chromatography (TLC) was performed using aluminum sheets precoated with silica gel $60 \mathrm{~F}_{254}$ purchased from Merck. Preparative plates were made by using glass supports precoated with silica gel $60 \mathrm{~F}_{254}$ with a layer thickness of $2 \mathrm{~mm}$ purchased from Merck. Column chromatography was carried out using silica gel 60, 230-400 mesh, from Chemie Brunschwig AG and neutral aluminum oxide gel from Fluka.

${ }^{1} \mathrm{H}$ and ${ }^{13} \mathrm{C}$ NMR spectra were obtained with Bruker Avance DRX-360 (360.13 MHz for $\left.{ }^{1} \mathrm{H}\right)$ or Bruker Avance DRX-400 (400.13 MHz for ${ }^{1} \mathrm{H}$ and $100.62 \mathrm{MHz}$ for ${ }^{13} \mathrm{C}$ ) spectrometers. Chemical shifts $(\delta)$ are given in ppm, and the coupling constant $(J)$ is given in Hertz, using the solvent itself as internal standard. The assignment of the ${ }^{1} \mathrm{H}$ and ${ }^{13} \mathrm{C}$ signals was performed by COSY and DEPT techniques.

Mass spectra were recorded either on a Vacuum Generators Micromass VG 70/70E (FAB ionization, nitrobenzylalcohol or dithranol AgOTf matrix of the sample) or on a HP 5988A Quadrupol (EI ionization, $70 \mathrm{eV}$ ) mass spectrometer. ESI and high-resolution mass spectra were recorded on a Brucker FTMS 4.7T BioAPEXII spectrometer. 


\section{Synthesis of [Os(bpy $)_{2}$-EPIP $]\left(\mathrm{PF}_{6}\right)_{2}$-Si-tripod-SAc (Os-SAc)}

cis-[O $\left.\mathrm{OsCl}_{2}(\mathrm{dmbpy})_{2}\right]$ (dmbpy $=4,4$ '-dimethyl-2,2'-bipyridine). This complex was prepared by a modified procedure of the reported method [42]. A mixture of $\left(\mathrm{NH}_{4}\right)_{2}\left[\mathrm{OsCl}_{6}\right](0.25 \mathrm{~g}, 0.57 \mathrm{mmol})$ and 2.0 equiv of 4,4'-dimethyl-2,2'-bipyridine $0.21 \mathrm{~g}, 1.14 \mathrm{mmol})$ in ethylenglycol $(10 \mathrm{ml})$ was refluxed for $2 \mathrm{~h}$ under Ar. The reaction mixture was stirred magnetically throughout this period. The cooled reaction mixture was treated with $1 \mathrm{M} \mathrm{Na}_{2} \mathrm{~S}_{2} \mathrm{O}_{4}(25 \mathrm{ml})$ to reduce any cis-[O- $\left.\mathrm{OsCl}_{2}(d m b p y)_{2}\right]^{+}$that might have formed. The dark violet-black precipitate was collected after the reaction mixture was cooled for $30 \mathrm{~min}$ in an ice bath. The solid was thoroughly washed with water and diethyl ether and was used in subsequent reactions without purification.

2-[4-(2-ethynyl)phenyl]-1H-imidazo[4,5-f][1,10]-phenanthroline (EPIP). A mixture of 1,10-phenanthroline-5,6-dione [43] (1.96g, $9.33 \mathrm{mmol})$, 4-ethynylbenzaldehyde (1.7 g, $13.06 \mathrm{mmol})$, ammonium acetate $(14.43 \mathrm{~g}, 0.187 \mathrm{~mol})$, and glacial acetic acid $(15 \mathrm{~mL})$ was refluxed for $4 \mathrm{~h}$ and then cooled to room temperature (RT). The reaction mixture was diluted with water, and dropwise addition of concentrated aqueous ammonia gave a yellow precipitate, which was collected, washed with water, and dried. The crude product obtained was purified by recrystallization from $\mathrm{CHCl}_{3} / \mathrm{MeOH}(4: 1, \mathrm{v} / \mathrm{v})$ and dried. Yield: $2.39 \mathrm{~g}(82 \%)$.

1H NMR: (DMSO- $d_{6}, 400 \mathrm{MHz}, \delta$ in ppm): 13.88 (br, $\left.1 \mathrm{H}\right), 9.00(\mathrm{dd}, 2 \mathrm{H}, J=4.3 \mathrm{~Hz}, J=1.5 \mathrm{~Hz})$, $8.91(\mathrm{dd}, 2 \mathrm{H}, J=8.1 \mathrm{~Hz}, J=1.8 \mathrm{~Hz}), 8.31(\mathrm{~d}, 2 \mathrm{H}, J=8.6 \mathrm{~Hz}), 7.81(\mathrm{dd}, 2 \mathrm{H}, J=8.4 \mathrm{~Hz}, J=4.6 \mathrm{~Hz})$, $7.68(\mathrm{~d}, 2 \mathrm{H}, J=8.3 \mathrm{~Hz}), 4.36(\mathrm{~s}, 1 \mathrm{H})$;

${ }^{13}$ C NMR: (DMSO- $d_{6}, 400 \mathrm{MHz}, \delta$ in ppm): $150.3,147.7,143.6,137.7,132.3,130.8,129.7$, $126.3,123.3,122.3,110.0,83.3,82.4$;

HRMS: calculated for $\mathrm{C}_{21} \mathrm{H}_{13} \mathrm{~N}_{4}\left[(\mathrm{M}+\mathrm{H})^{+}\right] 321.11347$, found 321.11380 .

[Os(dmbpy) $)_{2}$ (ethynyl-phenyl)imidazo-(1,10)-phenanthroline $]\left(\mathrm{PF}_{6}\right)_{2}$. A mixture of cis$\left[\mathrm{OsCl}_{2}\left(\right.\right.$ dmbpy $\left._{2}\right] \quad(0.29 \mathrm{~g}, 0.46 \mathrm{mmol}), 2$-(4-(2-ethynyl)phenyl)-1H-imidazo[4,5-f]-[1,10]phenanthroline $(0.16 \mathrm{~g}, 0.5 \mathrm{mmol})$, methoxyethanol $(15 \mathrm{~mL})$ and water $(5 \mathrm{~mL})$ was refluxed under Ar for $2 \mathrm{~h}$ to give a dark green solution. After most of the methoxyethanol solvent and the water were removed under reduced pressure, a precipitate was obtained by drop wise addition of a saturated aqueous $\mathrm{NH}_{4} \mathrm{PF}_{6}$ solution. The product was purified by column chromatography on alumina (acetonitrile/toluene 1:1) first to remove the ligand, and then eluting with a gradient of acetonitrile/water/saturated aqueous $\mathrm{KNO}_{3}$ from 100:1:1 to 100:18:2 to collect the complex. The collected fractions were combined and evaporated. An aqueous solution of saturated ammonium hexafluorophosphate was added. Filtration under vacuum with celite, washing with $\mathrm{H}_{2} \mathrm{O}$ and dissolution in acetone of the resulting precipitate afforded $0.345 \mathrm{~g}(64 \%)$ of the desired Os complex.

${ }^{1}$ H NMR: $\left(\mathrm{CD}_{3} \mathrm{CN}, 360 \mathrm{MHz}, \delta\right.$ in ppm): $8.70(\mathrm{~d}, 2 \mathrm{H}), 8.33(\mathrm{~d}, 4 \mathrm{H}), 8.26(\mathrm{~d}, 2 \mathrm{H}), 7.94(\mathrm{~d}, 2 \mathrm{H})$, $7.71(\mathrm{~d}, 2 \mathrm{H}), 7.65(\mathrm{t}, 2 \mathrm{H}), 7.55(\mathrm{~d}, 2 \mathrm{H}), 7.27(\mathrm{~d}, 2 \mathrm{H}), 7.23(\mathrm{~d}, 2 \mathrm{H}), 6.94(\mathrm{~d}, 2 \mathrm{H}), 3.59(\mathrm{~s}, 1 \mathrm{H}), 2.65$ $(\mathrm{s}, 6 \mathrm{H}), 2.53(\mathrm{~s}, 6 \mathrm{H})$. The imidazole proton cannot be seen under our experimental conditions.

HRMS: calculated for $\mathrm{C}_{45} \mathrm{H}_{36} \mathrm{~F}_{6} \mathrm{~N}_{8} \mathrm{OsP}\left[\left(\mathrm{M}-\mathrm{PF}_{6}\right)^{+}\right]$1025.23166, found 1025.22838; calculated for $\left.\mathrm{C}_{45} \mathrm{H}_{36} \mathrm{~N}_{8} \mathrm{Os}\left[\mathrm{M}-2 \mathrm{PF}_{6}\right)^{2+}\right]$ 440.13346, found 440.13364.

[Os(bpy $)_{2}$-EPIP] $\left(\mathrm{PF}_{6}\right)_{2}$-Si-tripod-SAc (Os-SAc). An oven-dried screw-cap tube was charged with tris[4-[3-(thiolacetatemethyl)-phenylethynyl]-phenyl]-4'-iodophenylsilane (Tripod-SAc) [39] (TripodSAc) (124 mg, $0.12 \mathrm{mmol}), \mathrm{Pd}(\mathrm{dba})_{2}(10 \mathrm{mg}, 0.01 \mathrm{mmol}), \mathrm{CuI}(4 \mathrm{mg}, 0.01 \mathrm{mmol})$, and $\mathrm{PPh}_{3}(16 \mathrm{mg}$, $0.03 \mathrm{mmol})$. The tube was capped with a septum, evacuated, and back-filled with Ar three times. $N, N$-diisopropylethylamine $(5 \mathrm{~mL})$ was added via syringe. A solution of $\left[\mathrm{Os}(\mathrm{dmbpy})_{2}\right.$-(ethynylphenyl)imidazo-(1,10)-phenanthroline $]\left(\mathrm{PF}_{6}\right)_{2}(117 \mathrm{mg}, 0.1 \mathrm{mmol})$ in THF $(5 \mathrm{~mL})$ was transferred via cannula to the tube. The tube was then capped with its screw cap, and the solution was stirred at RT for 2 days. The solvent was removed under reduced pressure to give a solid residue, which was dissolved in water $(5 \mathrm{~mL}), \mathrm{NH}_{4} \mathrm{PF}_{6}(0.25 \mathrm{~g})$ was added, and the resulting green precipitate was isolated by suction filtration. The precipitate was purified by column chromatography on alumina (acetonitrile/toluene 1:1) first to remove the unreacted [8] and then eluting with a gradient of acetonitrile/water/saturated 
aqueous $\mathrm{KNO}_{3}$ from 100:1:1 to 100:18:2. The collected green fractions were combined and evaporated. An aqueous solution of saturated ammonium hexafluorophosphate was added. Filtration under vacuum with celite, washing with $\mathrm{H}_{2} \mathrm{O}$ and dissolution in acetone, afforded the desired Os-complex-Tripod. Yield: $160 \mathrm{mg}(77 \%)$.

1H NMR: (d-DMSO, $360 \mathrm{MHz}, \delta$ in ppm): $14.48(\mathrm{br}, 1 \mathrm{H}), 8.82(\mathrm{~d}, 2 \mathrm{H}), 8.69(\mathrm{~m}, 5 \mathrm{H}), 8.39$ (s, 2H), 8.03-6.95 (m, 41H), $4.13(\mathrm{~s}, 6 \mathrm{H}), 2.63(\mathrm{~s}, 6 \mathrm{H}), 2.51(\mathrm{~s}, 6 \mathrm{H}), 2.36(\mathrm{~s}, 9 \mathrm{H})$.

ESI-MS: calculated for $\mathrm{C}_{102} \mathrm{H}_{78} \mathrm{~F}_{12} \mathrm{~N}_{8} \mathrm{O}_{3} \mathrm{OsP}_{2} \mathrm{~S}_{3} \mathrm{Si} 2068.4$, found $2068.4\left[\mathrm{M}^{+}\right]$.

HRMS: calculated for $\mathrm{C}_{102} \mathrm{H}_{78} \mathrm{~N}_{8} \mathrm{OsS}_{3} \mathrm{Si}\left[\left(\mathrm{M}-2 \mathrm{PF}_{6}\right)^{2+}\right]$ 889.23687, found 889.23473.

\section{Synthesis of $\left[\operatorname{Ir}(\mathrm{ppy})_{2}\right.$-(ethynylphenyl)-imidazo-(1,10)-phenanthroline](PF $\left.{ }_{6}\right)$}

According to a known method [40], a mixture of dichlorotetrakis[2-(2-pyridinyl)phenyl]diiridium(III) (64.3 mg, $0.06 \mathrm{mmol})$ and EPIP (38.4 mg, $0.12 \mathrm{mmol})$ in $\mathrm{MeOH} / \mathrm{CH}_{2} \mathrm{Cl}_{2}(40 \mathrm{~mL}, 1: 1)$ was heated under reflux under an inert atmosphere of $\mathrm{Ar}$ in the dark for $4 \mathrm{~h}$. The orange solution was then cooled to RT and $\mathrm{KPF}_{6}(26 \mathrm{mg}, 0.14 \mathrm{mmol}$ ) was added to the solution. The mixture was then evaporated to dryness and the solid was dissolved in $\mathrm{CH}_{2} \mathrm{Cl}_{2}$ and purified by column chromatography on silica gel. The desired product was eluted with $\mathrm{CH}_{2} \mathrm{Cl}_{2}$ /acetone (9:1). Subsequent recrystallization of the complex from a $\mathrm{CH}_{2} \mathrm{Cl}_{2}$ /diethyl ether mixture afforded the $\mathrm{Ir}(\mathrm{III})$ complex as yellow crystals. Yield: $42 \mathrm{mg}$ $(36 \%)$.

${ }^{1}$ H NMR: (DMSO- $d_{6}, 400 \mathrm{MHz}, \delta$ in ppm): 14.44 (br, $\left.1 \mathrm{H}\right), 9.17$ (d, 2H, $\left.J=8.4 \mathrm{~Hz}\right), 8.32(\mathrm{~d}, 2 \mathrm{H}$, $J=8.6 \mathrm{~Hz}), 8.27(\mathrm{~d}, 2 \mathrm{H}, J=8.4 \mathrm{~Hz}), 8.17(\mathrm{~d}, 2 \mathrm{H}, J=3.8 \mathrm{~Hz}), 8.11-8.08(\mathrm{~m}, 2 \mathrm{H}), 7.96(\mathrm{~d}, 2 \mathrm{H}, J=$ $7.1 \mathrm{~Hz}), 7.88(\mathrm{t}, 2 \mathrm{H}, J=8.0 \mathrm{~Hz}), 7.77(\mathrm{~d}, 2 \mathrm{H}, J=8.6 \mathrm{~Hz}), 7.51(\mathrm{~d}, 2 \mathrm{H}, J=5.6 \mathrm{~Hz}), 7.07(\mathrm{t}, 2 \mathrm{H}, J=$ 7.6Hz), 7.01-6.94 (m, 4H), $6.29(\mathrm{~d}, 2 \mathrm{H}, J=7.1)$.

${ }^{13}$ C NMR: (DMSO- $d_{6}, 100 \mathrm{MHz}, \delta$ in ppm): 168.6, 152.1, 145.4, 144.6, 137.2, 130.9, 129.6, 124.2, 123.2, 122.0, 119.3.

ESI-MS: calculated for $\mathrm{C}_{43} \mathrm{H}_{28} \mathrm{IrN}_{6}\left[\left({\mathrm{M}-\mathrm{PF}_{6}}^{+}\right]\right.$821.20, found 821.20.

HRMS: calculated for $\mathrm{C}_{43} \mathrm{H}_{28}{ }^{191} \mathrm{IrN}_{6}\left[\left({\mathrm{M}-\mathrm{PF}_{6}}^{+}\right]\right.$819.19759, found 819.19844.

\section{Synthesis of $\left[\operatorname{Ir}(p p y)_{2}\right.$-EPIP] $\left(\mathrm{PF}_{6}\right)$-Si-tripod-SAC}

An oven-dried screw-cap tube was charged with tris\{4-[3-(thiolacetatemethyl)-phenylethynyl]phenyl \}-4'-iodophenylsilane [Tripod-SAc] (124 mg, $0.121 \mathrm{mmol}), \mathrm{Pd}(\mathrm{dba})_{2}(10 \mathrm{mg}, 0.01 \mathrm{mmol}), \mathrm{CuI}$ (4 mg, $0.01 \mathrm{mmol}$ ), and $\mathrm{PPh}_{3}(16 \mathrm{mg}, 0.03 \mathrm{mmol})$. The tube was capped with a septum, evacuated, and back-filled with $\mathrm{Ar}$ three times. $N, N$-Diisopropylethylamine $(5 \mathrm{ml})$ was added via syringe. A solution of [ $\operatorname{Ir}(\mathrm{ppy})_{2}$-(ethynylphenyl)-imidazo(1,10)-phenanthroline $]\left(\mathrm{PF}_{6}\right)(96.6 \mathrm{mg}, 0.1 \mathrm{mmol})$ in THF $(5 \mathrm{~mL})$ was transferred via cannula to the tube. The tube was then capped with its screw cap and the solution was stirred at RT for 2 days. The solvent was removed under reduced pressure to give a solid residue, which was dissolved in water $(5 \mathrm{~mL}), \mathrm{NH}_{4} \mathrm{PF}_{6}(0.25 \mathrm{~g})$ was added, and the resulting red precipitate was isolated by suction filtration. The yellow-orange precipitate was purified by column chromatography on alumina (acetonitrile/toluene 1:1) first to remove the unreacted [Tripod-SAc] and then eluting with a gradient of acetonitrile/water/saturated aqueous $\mathrm{KNO}_{3}$ from 100:1:1 to 100:18:2. The collected orange fractions were combined and evaporated. An aqueous solution of saturated ammonium hexafluorophosphate was added. Filtration under vacuum with celite, washing with $\mathrm{H}_{2} \mathrm{O}$ and dissolution in acetone and evaporation of the solvent afforded the desired Ir-complex-Tripod-SAc as yellow powder. Yield: $162 \mathrm{mg}(87 \%)$.

1H NMR: $\left(\mathrm{CD}_{2} \mathrm{Cl}_{2}, 400 \mathrm{MHz}, \delta\right.$ in ppm): $12.18(\mathrm{br}, 1 \mathrm{H}), 9.24(\mathrm{~m}, 2 \mathrm{H}), 8.34(\mathrm{~d}, 2 \mathrm{H}, J=8.0 \mathrm{~Hz})$, $8.26(\mathrm{br}, 2 \mathrm{H}), 7.96(\mathrm{~d}, 2 \mathrm{H}, J=8.0 \mathrm{~Hz}), 7.82-7.20(\mathrm{~m}, 36 \mathrm{H}), 7.15-7.08(\mathrm{~m}, 4 \mathrm{H}), 7.00(\mathrm{dxd}, 2 \mathrm{H}, J=$ $7.4 \mathrm{~Hz}$ and $7.6 \mathrm{~Hz}), 6.84(\mathrm{~d}, 2 \mathrm{H}, J=5.6 \mathrm{~Hz}), 6.43(\mathrm{~d}, 2 \mathrm{H}, J=7.1 \mathrm{~Hz}), 4.11(\mathrm{~s}, 6 \mathrm{H}), 2.35(\mathrm{~s}, 9 \mathrm{H})$.

HR-MALDI: calculated for $\mathrm{C}_{100} \mathrm{H}_{70}{ }^{191} \mathrm{IrN}_{6} \mathrm{O}_{3} \mathrm{~S}_{3} \mathrm{Si} 1717.40412\left[\mathrm{M}-\mathrm{PF}_{6}\right]^{+}$, found 1717.40441 . 


\section{Photophysics}

Absorption spectra were measured on a Varian Cary 5000 double-beam UV-Vis-NIR spectrometer and baseline corrected. Steady-state emission spectra were recorded on a HORIBA Jobin-Yvon IBH FL-322 Fluorolog 3 spectrometer equipped with a $450 \mathrm{~W}$ xenon arc lamp, double grating excitation, and emission monochromators $(2.1 \mathrm{~nm} / \mathrm{mm}$ dispersion; 1200 grooves $/ \mathrm{mm})$ and a Hamamatsu R928 photomultiplier tube or a TBX-4-X single-photon-counting detector. Emission spectra were corrected for source intensity (lamp and grating) and emission spectral response (detector and grating) by standard correction curves. For monolayers, the sample was mounted on a commercially available solid-state sample holder provided by HORIBA Jobin-Yvon, and the emission was collected with the front face geometry. Time-resolved measurements were performed using the time-correlated single-photon counting (TCSPC) option on the Fluorolog 3. NanoLED ( $402 \mathrm{~nm}$; FWHM $<750 \mathrm{ps}$ ) with repetition rates between $10 \mathrm{kHz}$ and $1 \mathrm{MHz}$ were used to excite the sample. The excitation sources were mounted directly on the sample chamber at $90^{\circ}$ to a double-grating emission monochromator $(2.1 \mathrm{~nm} / \mathrm{mm}$ dispersion; 1200 grooves $/ \mathrm{mm}$ ) and collected by a TBX-4-X single-photon-counting detector. The photons collected at the detector are correlated by a time-to-amplitude converter (TAC) to the excitation pulse. Signals were collected using an IBH DataStation Hub photon counting module and data analysis was performed using the commercially available DAS6 software (HORIBA Jobin Yvon IBH). The goodness of fit was assessed by minimizing the reduced chi-squared function $\left(\chi^{2}\right)$ and visual inspection of the weighted residuals.

Quantum yield. Luminescence quantum yields $\left(\Phi_{\mathrm{em}}\right)$ were measured in optically dilute solutions (O.D. $<0.1$ at excitation wavelength) and compared to reference emitters by the following equation:

$$
\Phi_{x}=\Phi_{r}\left[\frac{A_{r}\left(\lambda_{r}\right)}{A_{x}\left(\lambda_{x}\right)}\right]\left[\frac{I_{r}\left(\lambda_{r}\right)}{I_{x}\left(\lambda_{x}\right)}\right]\left[\frac{n_{x}^{2}}{n_{r}^{2}}\right]\left[\frac{D_{x}}{D_{r}}\right]
$$

where $A$ is the absorbance at the excitation wavelength $(\lambda), I$ is the intensity of the excitation light at the excitation wavelength $(\lambda), n$ is the refractive index of the solvent, $D$ is the integrated intensity of the luminescence and $\Phi$ is the quantum yield. The subscripts $r$ and $x$ refer to the reference and the sample, respectively. All quantum yields were performed at identical excitation wavelength for the sample and the reference, canceling the $I\left(\lambda_{r}\right) / I\left(\lambda_{x}\right)$ term in the equation. Os(bpy $)_{3}{ }^{2+}(\Phi=0.005$ in deaerated acetonitrile solution) [44]. Deaerated samples were prepared by the freeze-pump-thaw technique.

\section{Electrochemical characterization Os-SAc in solution and in SAMs on Au surface}

The electrochemical characterization (cyclic voltammetry, CV, and differential pulse voltammetry, DPV) for the metal complex herein reported has been performed in acetonitrile/0.1 M tetra-butylammonium hexafluorophosphate (TBAH). Glassy carbon and Au have been employed as working electrodes for solution or SAMs studies respectively, $\mathrm{Pt}$ wire as counter, and $\mathrm{Pt}$ wire as quasi-reference (QRE) electrode.

Electrochemical apparatus and procedures. Acetonitrile (Sigma-Aldrich, Chromasolv® Plus, $99.9 \%$ ) was used as arrived without any further purification. TBAH, electrochemical grade, $99 \%$, Fluka, was used as supporting electrolyte, which was recrystallized from a 1:1 ethanol-water solution and dried at $60{ }^{\circ} \mathrm{C}$ under vacuum.

For the electrochemical experiments, a CHI750C Electrochemical Workstation (CH Instruments, Austin, TX, USA) was used. The electrochemical experiments were performed in a glass cell under an Ar atmosphere. To minimize the ohmic drop between the working and the reference electrodes, the feedback correction was employed.

The electrochemical experiments were performed by using 3-mm-diameter glassy carbon (GC homemade from Tokai glassy carbon rod) disk electrode (for species free to diffuse in solution), and 
1-mm-diameter Au-disk electrode (for species self-assembled on the surface). The electrodes were stored in ethanol, and were polished before experiments with a $0.05 \mu \mathrm{m}$ diamond suspension (Metadi Supreme Diamond Suspension, Buehler) and ultrasonically rinsed with ethanol for $5 \mathrm{~min}$. The electrodes were electrochemically activated in the background solution by means of several voltammetric cycles at $0.5 \mathrm{~V} \mathrm{~s}^{-1}$ between the anodic and cathodic solvent/electrolyte discharges, until the same quality features were obtained. The reference electrode was Pt quasi-reference electrode (Pt-QRE), which was separated from the catholyte by glass frits. The reference electrode was calibrated at the end of each experiment against the ferrocene/ferricenium couple, whose formal potential is $0.450 \mathrm{~V}$ against the $\mathrm{KCl}$ saturated calomel electrode (SCE); in the following, all potential values will be reported against SCE. A Pt ring or coil served as the counter electrode.

The SAMs have been prepared by immersing the Au-disk electrode in a freshly prepared $1.0 \mathrm{mM}$ solution of acetylthiol derivative of the metal complex in neat acetonitrile, and left to form monolayers overnight. Before use, the sample has been rinsed with several $\mathrm{mL}$ of absolute ethanol and acetone and gently blown dry with Ar. The effective area of the working electrode has been measured upon evaluation of the peak current of ferricenium/ferrocene redox couple at different scan rate, before the formation of the SAMs and after its electrochemical desorption.

\section{Surface analysis}

Atomic force microscopy (AFM) imaging. AFM images of the monolayers on flat Au substrates were acquired in air at RT with a commercial instrument (Digital Instruments, Nanoscope IIIa, Dimension 3000, Santa Barbara, CA) operating in tapping mode. AFM images are flattened and shown without further modification. Analysis was performed using WSxM 4.0 Develop.

Fluorescence lifetime microscopy (FLIM). The FLIM images and the fluorescence decays on surfaces were recorded using a Microtime 200 (PicoQuant) attached to an Olympus IX 71 microscope with a $100 \times$ oil-immersion objective and a scanning speed of $6 \mu$ s per point at an excitation with a 440 -nm laser (FWHM 80 ps). Fluorescent lifetimes were calculated from the whole area by the software SymphoTime (PicoQuant).

Preparation of Os-SAc SAMs. For the SAMs, we need a Au surface with a very high degree of flatness. Hence, ultraflat Au substrates were prepared on microscope cover slip using the template stripping (TS) method as described by Weiss and co-workers [45]. Briefly, first the Au was evaporated on Si wafers and then, by using Optical Adhesive (Norland 61), glued on the cleaned (sonicated in EtOH and Plasma activated) microscope cover slips and curing for $2 \mathrm{~h}$ under UV light (200 W Hg lamp with 280-400 $\mathrm{nm}$ dichroic filter). The glass substrates were cleaved off the Si-waver by using a razor blade after which the TS Au substrates were immersed in a solution of $2 \mathrm{mM}$ of Os-SAc in ethanol for $24 \mathrm{~h}$ at RT for the monolayer formation. The samples were subsequently rinsed with EtOH to remove any unbound molecules.

Formation of the junctions. Ultraflat Au surfaces were formed by a TS procedure published previously [46]. All the details can be found in ref. [45] but a brief description is given here. On Si wafers with their native $\mathrm{SiO}_{2}$ layer present a layer of $500 \mathrm{~nm}$ of Au was thermally deposited by electron-beam (e-beam) at $2-3 \times 10^{-6}$ Torr at a rate of $8-10 \AA$ A/s. Glass slides, which were cleaned by washing with EtOH and oxygen plasma oxidation for $5 \mathrm{~min}$, of typically $1 \mathrm{~cm}^{2}$ were glued at the Au surface using an optical adhesive (Norland, No. 61). The optical adhesive was cured for $2 \mathrm{~h}$ by exposure to ultraviolet light. The glass substrates were cleaved off the Si-wafer by using a razor blade after which the TS Au substrates were immersed in a solution of $2 \mathrm{mM}$ of Os-SAc in ethanol/acetonitrile for $24 \mathrm{~h}$ at RT. After SAM formation, the samples were rinsed with $\mathrm{EtOH}$.

We used cone-shaped eutectic indium-gallium (EGaIn, $75.5 \%$ Ga $24.5 \%$ by weight, $15.7{ }^{\circ} \mathrm{C}$ melting point) alloy as top electrodes. A detailed description of the formation and contacting the SAMs by EGaIn top electrodes have been reported by our group [47]. The EGaIn is a non-Newtonian fluid. On the micrometer scale, EGaIn behaves as a solid, but when sheer-pressure is applied EGaIn behaves 
as a liquid. The EGaIn will flow until the sheer-pressure is relieved. This behavior allows, unlike mercury, to shape the EGaIn into non-spherical shapes. A drop of EGaIn hanging at a 26S-gauge needle was brought into contact with a surface that is wettable by EGaIn, such as PDMS, glass, or Ag surfaces. The EGaIn adheres to both the surface and to the needle. Slowly retracting the needle from the EGaIn-drop, by using a micromanipulator, deforms the EGaIn drop in such a way that two cone-shaped EGaIn structures connected head-to-head arise. Further retraction of the needle results into separation of the cone-shaped EGaIn structures, one at the needle and one at the surface. Subsequently, the substrate was discarded and replaced by a TS Au surface with the SAM of interest and the cone-shaped EGaIn at the needle was brought into contact with the SAM.

\section{RESULTS AND DISCUSSION}

All the chemical formulas of the investigated compounds are shown in Scheme 1.

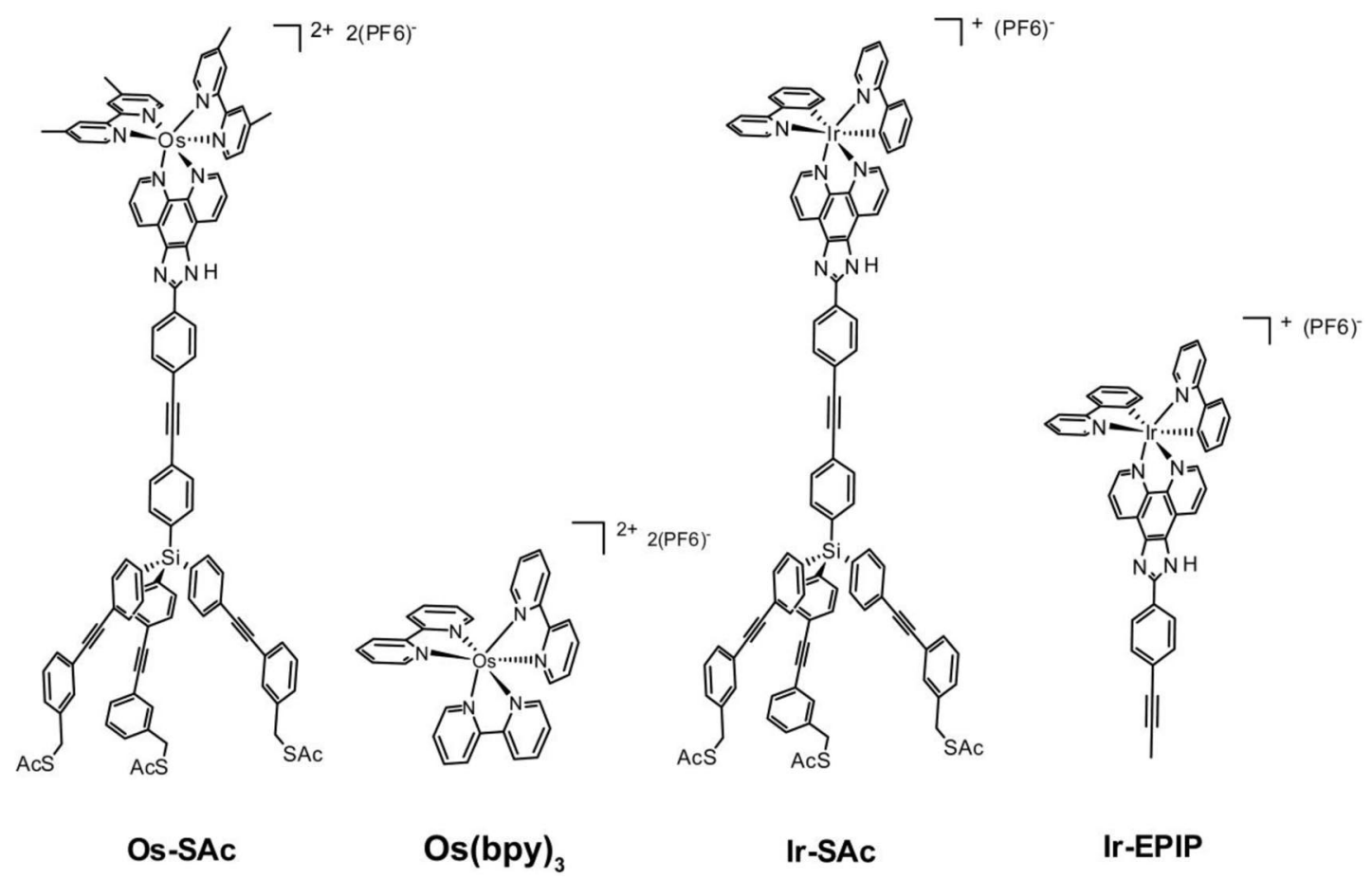

Scheme 1 Schematic formulas of the Ir and Os tripodal complex investigated along with their respective reference compounds. The molecules will be named with the abbreviation shown under the structure. To evidence the tripodal structure and the possible geometry adopted on the surface the anchoring groups are drawn all in the same direction.

\section{Synthesis}

The synthetic scheme for Os-SAc is depicted in Scheme 2. 1,10-Phenanthroline-5,6-dione and 4-ethynylbenzaldehyde were coupled together under acidic condition $\left(\mathrm{AcOH}\right.$ and $\mathrm{NH}_{4} \mathrm{OAc}$ ) yielding the new ligand EPIP in good yield. 


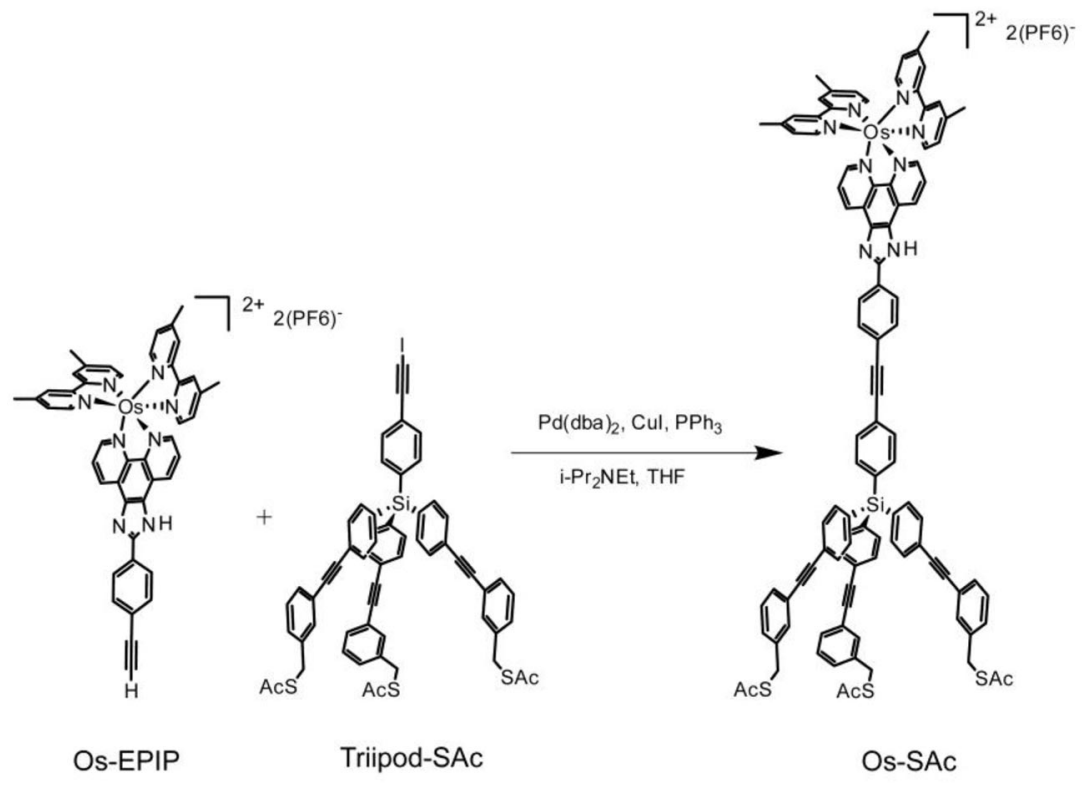

Scheme 2 General synthetic scheme for the Os-SAc complex.

The new ligand was incorporated into the Os precursor cis-[OSCl$\left.(\mathrm{dmbpy})_{2}\right]$ by a substitution reaction of the two chloride anions. The last step of the synthesis protocol was the coupling reaction of the Os complex with the tripod-SAc compound under Sonogashira conditions (yield: $83 \%$ ). The tripod-SAc unit was prepared following literature procedures [39] .

The synthetic route for Ir-SAc is presented in Scheme 3. The compound Ir-SAc was prepared under similar conditions as for the compound Os-SAc. The metal complex dichlorotetrakis[2-(2-

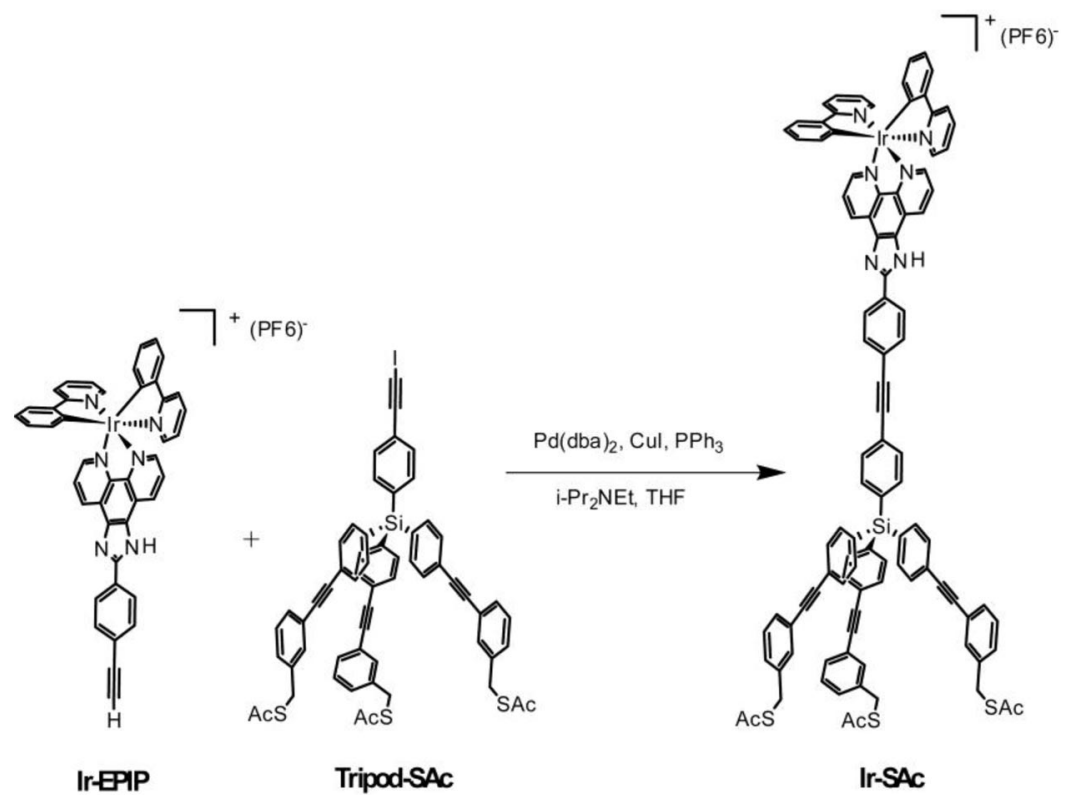

Scheme 3 Schematic synthetic route for the Ir-Sac complex. 
pyridinyl]phenyldiiridium(III) was used to introduce the $\operatorname{Ir}$ fragment bis[2-(2-pyridinyl)phenyl]iridium(III) into the octahedral $\left[\operatorname{Ir}(\mathrm{ppy})_{2}\right.$-ethynyl)phenyl)-imidazo-(1,10)-phenanthroline $\left(\mathrm{PF}_{6}\right)$ target compound. The Sonogashira-coupling was performed under the same conditions as for the Os-SAc compound to achieve the final metal complex Ir-SAc in $87 \%$ yield.

\section{Photophysical characterization in solution}

Photophysical properties of Os-SAc. The absorption spectra of Os-SAc, and the reference compound Os $(\text { bpy })_{3}\left(\mathrm{PF}_{6}\right)^{2}$ in acetonitrile solutions are shown in Fig. 1. The high energy bands at $291 \mathrm{~nm}(\varepsilon=$ $8.5 \times 10^{4} \mathrm{M}^{-1} \mathrm{~cm}^{-1}$ ) can be assigned to the bipyridine and phenanthroline singlet intraligand ( $\left.{ }^{1} \mathrm{IL}\right) \pi-\pi^{*}$ transitions while the $311 \mathrm{~nm}\left(\varepsilon=5.2 \times 10^{4} \mathrm{M}^{-1} \mathrm{~cm}^{-1}\right)$ and $340 \mathrm{~nm}\left(\varepsilon=2.5 \times 10^{4} \mathrm{M}^{-1} \mathrm{~cm}^{-1}\right)$ are due to the $\pi-\pi^{*}$ absorptions of the highly conjugated moieties containing the phenylene-ethylene moieties. In particular, the latter is due to the EPIP [48] while the former is attributed to the tripod species. This assignment is corroborated by the observation that for the reference non-tripodal complex, Os(bpy $)_{3}$, this $311-\mathrm{nm}$ feature is missing. The lower energy bands between 440 and $550 \mathrm{~nm}$ (for the 490-nm band the $\varepsilon=1.1 \times 10^{4} \mathrm{M}^{-1} \mathrm{~cm}^{-1}$ ) are assigned to the singlet metal to ligand charge transfer ( $\left.{ }^{1} \mathrm{MLCT}\right)$ transitions, which are typical for Os polypyridyl complexes [49,50], involving the $d$ orbitals of the Os and the $\pi^{*}$ orbitals of the substituted bipyridines and phenanthroline ligands. The lowest ${ }^{1}$ MLCT band for the Os-SAc feature is red-shifted by $10 \mathrm{~nm}$ as compared to the reference compound. This shift can be explained by a combined effect of the slight electron-donating character of the two methyl groups on the bipyridines, which would favor the MLCT transitions to the substituted phenanthroline, and the larger delocalization of this ligand vs. the unsubstituted phenanthroline, which lower the lowest unoccupied molecular orbital (LUMO) of such a ligand.

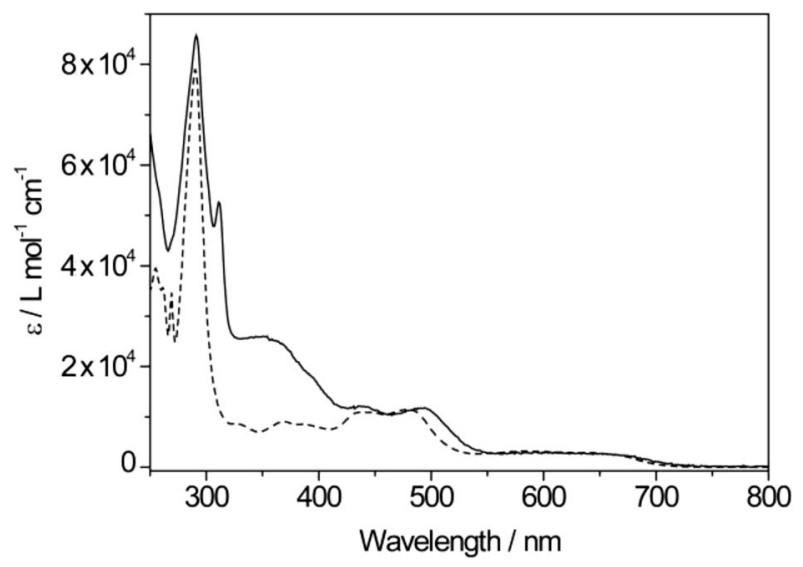

Fig. 1 Absorption spectra of Os-SAc (-) and Os(bpy) ${ }_{3}(---)$ in acetonitrile solution.

Both the complexes exhibit broad and weak absorption features $\left(\varepsilon=2.9 \times 10^{3} \mathrm{M}^{-1} \mathrm{~cm}^{-1}\right)$ in the $550-700 \mathrm{~nm}$ region, which are attributed to the spin forbidden transition from the ground state to the ${ }^{3}$ MLCT level, partly allowed because of the large spin-orbit coupling induced by the heavy Os [51,52]. Room temperature emission spectra of Os-SAc and $\mathrm{Os}(\mathrm{bpy})_{3}$ in acetonitrile solution upon excitation at $480 \mathrm{~nm}$ are shown in Fig. 2. These complexes emit in the red part of the electromagnetic spectrum and are characterized by broad structureless bands. As for other Os polypyridine complexes, the emission is due to the radiative deactivation of the ${ }^{3} \mathrm{MLCT}$ state and the features are characteristic of metal to ligand charge-transfer bands [49,53]. Os-SAc has the emission maximum at $768 \mathrm{~nm}$, which is red-shifted by about $37 \mathrm{~nm}$ as compared to $\mathrm{Os}(\mathrm{bpy})_{3}$ which is consistent with the trend observed in 


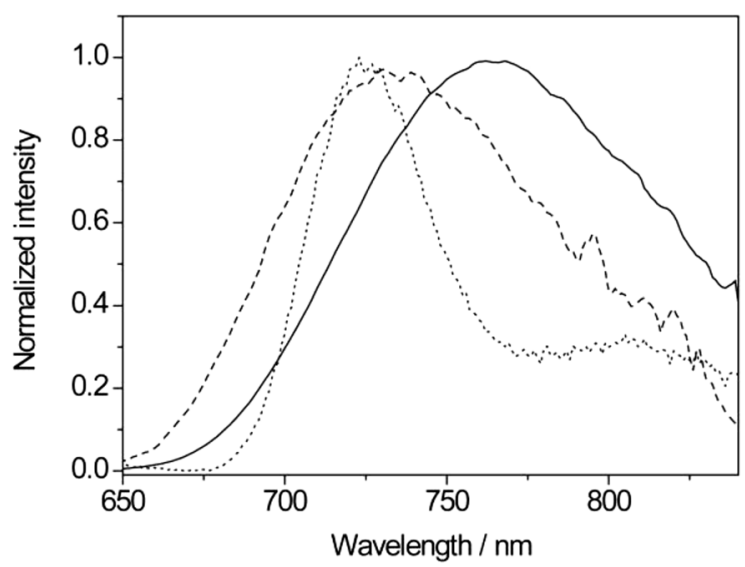

Fig. 2 Room-temperature emission spectra of Os-SAc (-) and Os(bpy) ${ }_{3}(---)$ in acetonitrile solution. $\lambda_{\text {ex }}=480$ $\mathrm{nm}$. Emission spectrum of Os-SAc measured at $77 \mathrm{~K}(\cdots)$ in butyronitrile matrix.

absorption (see above). The lowest excited state ${ }^{3}$ MLCT involves the substituted phenantroline ligand. Lowering the temperature to $77 \mathrm{~K}$, the emission undergoes a blue-shift of $45 \mathrm{~nm}$, and is characterized by a vibronic progression. Such a behavior is again typical for metal-to-ligand charge transfer (MLCT) emissions, since at $77 \mathrm{~K}$, the solvent molecules are frozen and hence any stabilization of the chargetransfer transitions involving the solvent is absent and consequently, the HOMO-LUMO gap is increased. The photophysical data are summarized in Table 1 . The excited-state lifetimes are consistent with the assignment of the luminescent state. They are in the range of 30-40 ns for the Os complexes investigated in aerated solutions. The excited-state lifetime measured at $77 \mathrm{~K}$, as can be seen from Table 1, is much longer than that measured at RT.

Table 1 Photophysical data in acetonitrile solution, otherwise specified and on surface, of the Os-SAc and the reference compound.

\begin{tabular}{lcccccccc}
\hline Complex & \multicolumn{9}{c}{ Emission, RT } & \multicolumn{2}{c}{ Emission, 77 K } \\
\cline { 2 - 5 } & $\begin{array}{l}\lambda_{\max } \\
(\mathrm{nm})\end{array}$ & $\phi^{\mathrm{a}}$ & $\phi^{\mathrm{b}}$ & $\begin{array}{c}\tau^{\mathrm{a}} \\
(\mathrm{ns})\end{array}$ & $\begin{array}{c}\tau^{\mathrm{b}} \\
(\mathrm{ns})\end{array}$ & $\begin{array}{c}\lambda_{\max }^{\mathrm{c}} \\
(\mathrm{nm})\end{array}$ & $\begin{array}{c}\tau^{\mathrm{c}} \\
(\mathrm{ns})\end{array}$ \\
\hline Os-SAc & 768 & 0.004 & 0.006 & 26 & 76 & 723,805 & 718 \\
Os(bpy) & 743 & 0.0035 & 0.005 & 37 & 60 & 705,781 & 1800 \\
Os-SAc-Gold & - & - & - & 2.1 & - & & \\
Os-SAc-Glass & - & - & - & 7.8 & - & & \\
\hline
\end{tabular}

an air-equilibrated solution.

$\mathrm{b}$ In degassed solution.

' In butyronitrile glass. For lifetime measurements, 431-nm laser diode was used as excitation source. For lifetime on Au and on glass, 440-nm laser excitation was used.

Photophysical properties of Ir-SAc. Electronic absorption spectra of Ir-SAc and the reference compound Ir-EPIP are shown in Fig. 3. In both cases, the lowest energy bands around 400-450 nm $\left(\varepsilon=5.5 \times 10^{3} \mathrm{dm}^{3} \mathrm{~mol}^{-1} \mathrm{~cm}^{-1}\right)$ are attributed to the singlet and triplet MLCT electronic transitions [54] involving the $d$ orbitals of the Ir metal ion and the EPIP ligand. However, the absorption of the tripodal molecule, Ir-SAc, varies significantly from the parent compound, Ir-EPIP, in the higher energy region, since the latter compound lacks the bands of the tripodal ligand, Tripod-SAc. 


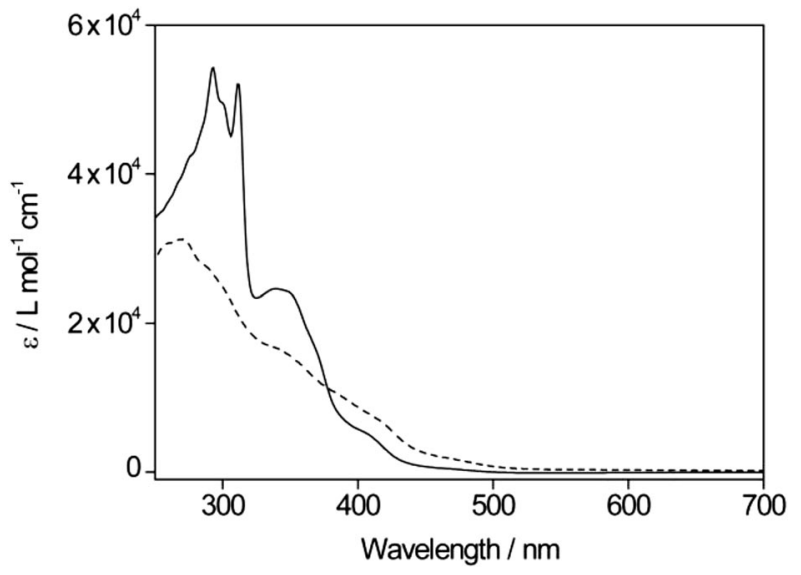

Fig. 3 Absorption spectra of Ir-SAc (-) and Ir-EPIP (----) in acetonitrile solution.

The highest energy band at $294 \mathrm{~nm}\left(\varepsilon=5.4 \times 10^{4} \mathrm{dm}^{3} \mathrm{~mol}^{-1} \mathrm{~cm}^{-1}\right)$ is attributed to the transitions involving the three ligands coordinated to the central metal ion. Two features characteristics for the Ir-SAc absorption spectrum are the bands around $311 \mathrm{~nm}\left(\varepsilon=5.2 \times 10^{4} \mathrm{dm}^{3} \mathrm{~mol}^{-1} \mathrm{~cm}^{-1}\right)$ and $341 \mathrm{~nm}$ $\varepsilon=2.5 \times 10^{4} \mathrm{dm}^{3} \mathrm{~mol}^{-1} \mathrm{~cm}^{-1}$ ), respectively. They are both due to the presence of the $p$-phenyleneethylene units [48], and to the tripod species, respectively. This assignment is also consistent with the tripodal systems of Ru [24] and Os (Fig. 1) that have identical ancillary tripodal ligand.

The RT emission spectra of Ir-SAc and Ir-EPIP in acetonitrile solution are presented in Fig. 4. As expected, both these complexes have an almost identical emission profile. Ir-SAc has an emission maximum at $582 \mathrm{~nm}$, whereas for the reference compound, the emission maximum is at $579 \mathrm{~nm}$. The emission at RT of both complexes is attributed to the decay of the ${ }^{3}$ MLCT [54-57], and hence the emission profile has a broad and structureless feature at RT. Also, as already mentioned, the ligand involved in the charge transfer is the substituted phenanthroline and therefore both complexes have very similar emission maxima, since the extent of exciton diffusion on this ligand is very similar. At $77 \mathrm{~K}$ the emission is blue-shifted significantly (maximum at $525 \mathrm{~nm}$ ) and exhibits a vibronic progression. In rigid matrices the excited states can mix with the lowest triplet ligand centered $\left({ }^{3} \mathrm{LC}\right)$ states. Such mixing can be extremely high as reflected in the elongation of the excited-state lifetime. In our cases at $298 \mathrm{~K}$, these
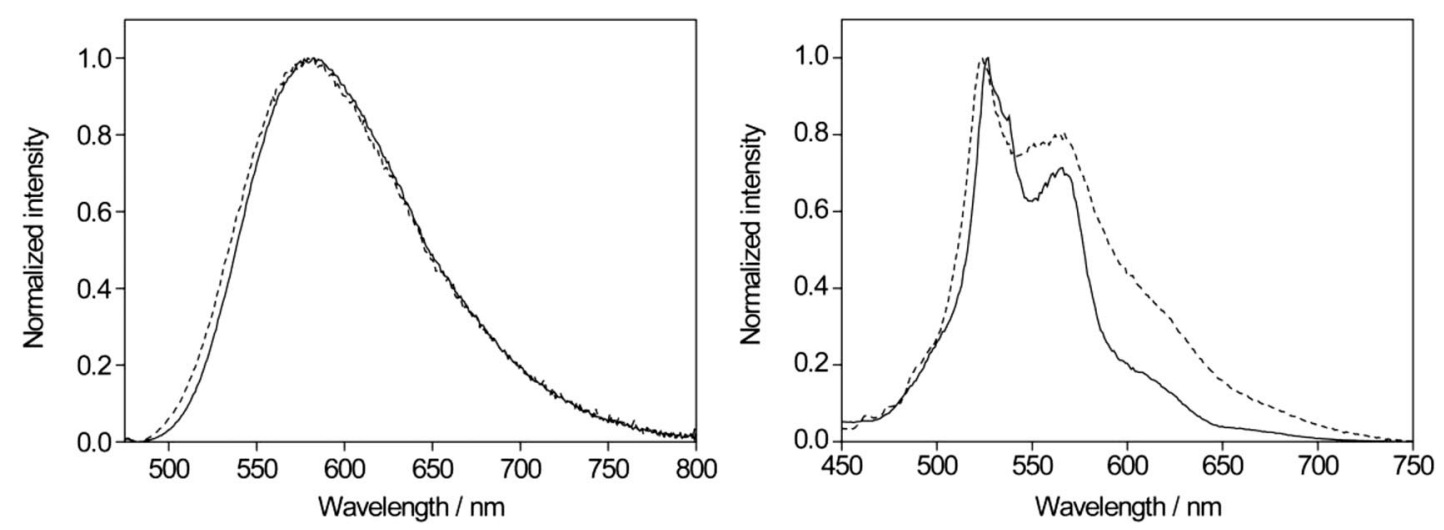

Fig. 4 (left) RT emission spectra of Ir-SAc (-) and Ir-EPIP (----) in acetonitrile solutions. (right) Emission spectrum of Ir-SAc (-) and Ir-EPIP (----) measured at $77 \mathrm{~K}$ in butyronitrile matrix. $\lambda_{\mathrm{ex}}=410 \mathrm{~nm}$. 
complexes have, in deaerated solution, excited-state lifetimes of about $1 \mu \mathrm{s}$, which is typical for $\operatorname{Ir}(\mathrm{III})$ complexes. At $77 \mathrm{~K}$ we observe a double exponential decay with 2 components: a short component with a lifetime of about $7 \mu \mathrm{s}$, and a long component of about $100 \mu \mathrm{s}$. This last one is definitely a triplet state localized on the ethynylphenyl substituent of the phenanthroline ligand. The two states, ${ }^{3}$ MLCT and the ${ }^{3} \mathrm{LC}$ state, are not completely equilibrated resulting in a biexponential decay. Such effects have been reported in literature for various Re polypyridyl complexes [58]. Due to the triplet character of the emission, the emission quantum yields of these phosphorescent complexes are strongly dependent on the presence of oxygen. The complete photophysical data of these complexes are presented in Table 2 .

Table 2 Photophysical data in acetonitrile solution, otherwise specified, of the Ir-SAc and Ir-EPIP.

\begin{tabular}{|c|c|c|c|c|c|c|c|}
\hline \multirow[t]{2}{*}{ Complex } & \multicolumn{5}{|c|}{ Emission, RT } & \multicolumn{2}{|c|}{ Emission, $77 \mathrm{~K}$} \\
\hline & $\begin{array}{l}\lambda_{\max } \\
(\mathrm{nm})\end{array}$ & $\phi^{\mathrm{a}}$ & $\phi^{\mathrm{b}}$ & $\begin{array}{c}\tau^{\mathrm{a}} \\
(\mu \mathrm{s})\end{array}$ & $\begin{array}{c}\tau^{b} \\
(\mu s)\end{array}$ & $\begin{array}{l}\lambda_{\max }{ }^{c} \\
(\mathrm{~nm})\end{array}$ & $\begin{array}{c}\tau_{1}, \tau_{2}^{\mathrm{c}} \\
(\mu \mathrm{s})\end{array}$ \\
\hline Ir-SAc & 582 & 0.34 & 0.03 & 1.1 & 0.257 & 525,560 & $\begin{array}{c}6.7(0.85), \\
109(0.15)\end{array}$ \\
\hline Ir-EPIP & 579 & 0.14 & 0.02 & 1.0 & 0.214 & 524,567 & $\begin{array}{r}7.1(0.81) \\
101(0.19)\end{array}$ \\
\hline
\end{tabular}

an degassed solution.

b In air-equilibrated solution.

${ }^{\mathrm{c}}$ In butyronitrile glass. For lifetime measurements, 402-nm laser diode was used as excitation source.

SAMs. The AFM picture (Fig. 5) shows that the monolayer was formed with a reasonable quality although it is not perfectly homogeneous. Similar trends were observed by us even for the Ru tripod on Au surface. However, from the depth profile, it is clear that it was a monolayer as the length of the molecule is about $3 \mathrm{~nm}$. Further, when a control experiment was performed by immersing a bare $\mathrm{Au}$ surface in the ethanolic solution under identical conditions, it revealed no such depth profile supporting our claim that the features on the AFM are indeed due to the monolayer formation and not to the surface roughness of the Au (roughness $0.16 \mathrm{~nm}$ RMS).
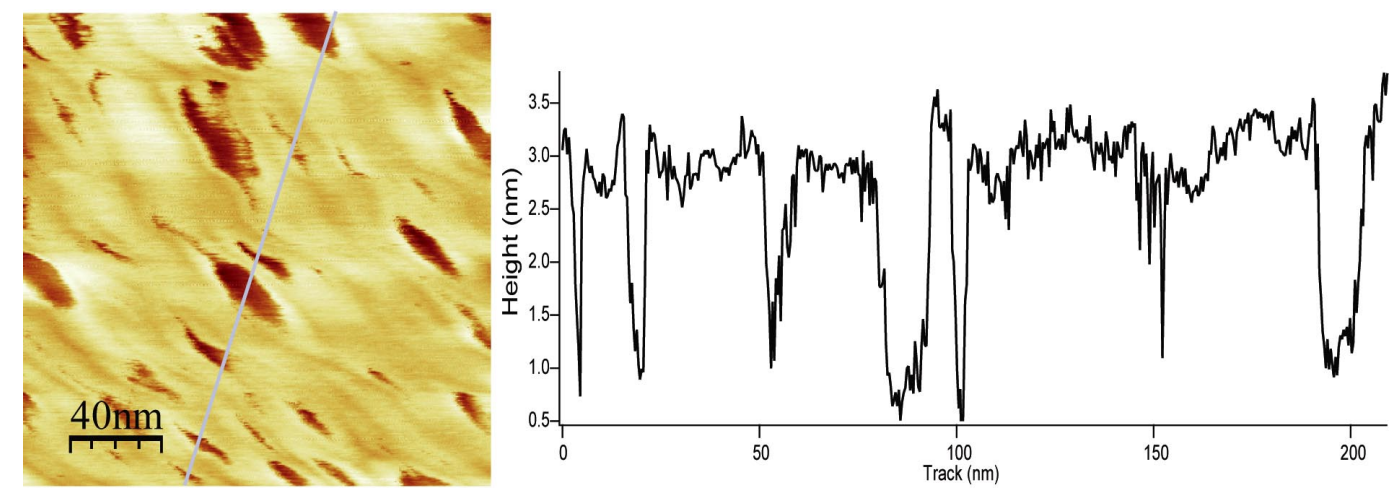

Fig. 5 AFM picture of SAM of Os-SH on Au substrate and height profile, revealing a reasonable monolayer quality with heights corresponding to the dimensions of the molecule. 
Photophysical measurements of Os-SAc monolayer. The emission from the monolayer was too weak to be able to record a spectrum in our spectrofluorimeter. However, the excited-state lifetimes were measured using a time-resolved confocal microscope and resulted to be $2.1 \mathrm{~ns}$ (see Table 1). This lifetime is significantly shorter than what is normally observed for Os-SAc in solution. However, in order to estimate the role played by the Au surface in the quenching of the lifetime of Os-SAc, we prepared a dilute solution of Os-SAc in acetonitrile, and drop cast on a glass surface. Since glass surface should not have any influence on the emission of Os-SAc, the obtained lifetime was used as a reference for unquenched lifetime on an inert surface. The lifetime of Os-SAc on glass was found to be $7.8 \mathrm{~ns}$. The quenching on glass compared to the excited-state lifetime in solution is most likely due to triplet-triplet annihilation since on the glass surface we expect the molecules of Os complex very close to each other. The origin of quenching on Au is attributed to a photoinduced electron transfer from the redox-active Os core to the electron-deficient Au surface. Similar effects with Ru tripod were observed by us, as well as other groups, with different Ru complexes on Au [24,31,59-63]. Using the quenched and unquenched lifetimes, we can estimate the electron-transfer rate using the following equation:

$$
k_{\mathrm{eT}}=1 / \tau-1 / \tau_{0}
$$

where $\tau$ is the quenched lifetime and $\tau_{0}$ is the unquenched lifetime. For the present system, it was found that electron-transfer rate constant was $3.5 \times 10^{8} \mathrm{~s}^{-1}$. This value is similar to the one obtained for $\mathrm{Ru}$ tripod on Au surface. However, this electron-transfer rate is significantly faster (2-3 orders) than the ones reported by Unwin et al. [60] and Kamat and coworkers [59] for Ru complexes on different surfaces. This observation is consistent with the fact that due to extensive conjugation of the ligand anchored to the surface, the electron-transfer rate is significantly higher in our tripodal systems.

Electrochemical characterization of unbound Os-SAc in solution. The electrochemical characterization for a $0.5 \mathrm{mM}$ Os-SAc unbound species was performed in $\mathrm{CH}_{3} \mathrm{CN} / 0.1 \mathrm{M}$ TABH by means of $\mathrm{CV}$ and it is displayed in Fig. 6. The first reduction appears as an irreversible peak at $-1.10 \mathrm{~V}$ (see Fig. 6). This is expected to involve the ligand having the most stable LUMO [64-66], as the phenanthroline-derivative moiety in our case. This behavior has been observed previously on similar Ru complexes $[67,68]$. The successive reduction process at $-1.27 \mathrm{~V}$, which can be attributed to the reduction of the bipyridine ligand, is reversible at all scan rates, as well as the first oxidation at $+0.83 \mathrm{~V}$, which can be attributed to the oxidation of the Os center Os(III)/Os(II).

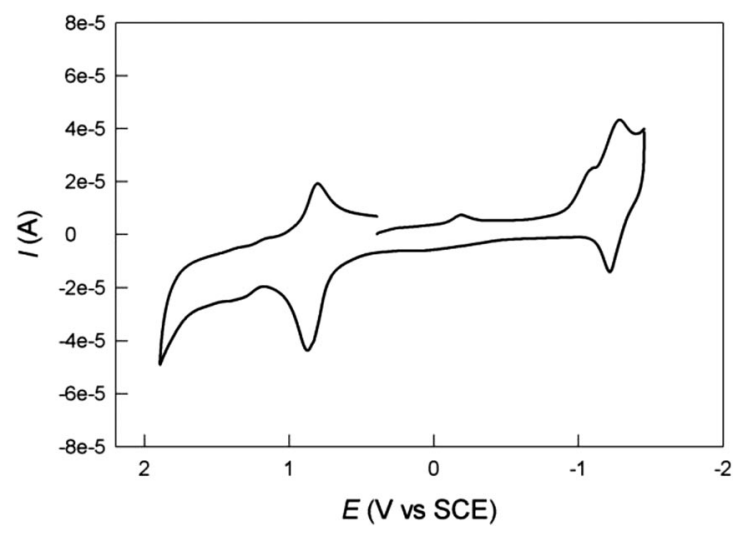

Fig. $6 \mathrm{CV}$ of $0.5 \mathrm{mM}$ solution of Os-SAc in $\mathrm{CH}_{3} \mathrm{CN} / 0.1 \mathrm{M}$ TBAH. Scan rate $0.1 \mathrm{~V} \mathrm{~s}^{-1}$. Working electrode: glassy carbon; counter: Pt coil; reference: Pt QRE. Calibration vs. SCE with $\mathrm{Fc}^{+} / \mathrm{Fc}$ as internal standard. 
Complete electrochemical data of this system are reported in Table 3. The data obtained from the DPV (not shown here) are also reported in Table 3. The standard potentials, referenced against SCE, are calculated as the average value between cathodic and anodic peak potentials as the scan rate is varied in the range $0.1-5 \mathrm{~V} \mathrm{~s}^{-1}$. The peak to peak separation is about $90 \mathrm{mV}$, which is larger than the expected for an ideal Nernstian behavior $(59 \mathrm{mV})$. However, the behavior of the redox couple ferrocene/ferricenium, used as internal standard, showed the same trend. Therefore, we can attribute the observed effect to the ohmic drop of the system, as previously reported for aprotic media by Bard and co-workers [69]. Furthermore, the peak current for both the redox processes under investigation increases linearly with the square root of the scan rate, as expected for a diffusion-controlled electrochemical process. The values for the HOMO-LUMO gap are also reported in the Table 3, and are estimated as the difference between the standard potential for the first oxidation and the first reduction respectively. Also, the values of HOMO and LUMO are calculated based on the value of $-4.8 \mathrm{eV}$ for ferrocene with respect to vacuum level as previously reported [70]. Furthermore, concerning the oxidation process, the value for the standard potential of the species free to diffuse in solution is matching, within the experimental error, that of the species directly bound to the electrode surface through the SAMs (see next section).

Table 3 Electrochemical data in acetonitrile solution, otherwise specified, of the Os-SAc and Os-SAc SAM on $\mathrm{Au}$.

\begin{tabular}{lcccc}
\hline Measurement & \multicolumn{4}{c}{ Potentials } \\
\cline { 2 - 5 } & $\begin{array}{c}E_{\mathrm{ox}}[\mathrm{HOMO}] \\
(\mathrm{V})\end{array}$ & $\begin{array}{c}E_{\text {red, } 1}[\mathrm{LUMO}] \\
(\mathrm{V})\end{array}$ & $\begin{array}{c}E_{\text {red, } 2} \\
(\mathrm{~V})\end{array}$ & $\begin{array}{c}\Delta E_{\text {HOMO-LUMO }} \\
(\mathrm{V})\end{array}$ \\
\hline $\mathrm{CV}$ & $+0.834 \pm 0.003 \mathrm{r}$ & $-1.100 \pm 0.005 \mathrm{ir}$ & $-1.272 \pm 0.004 \mathrm{r}$ & $1.934 \pm 0.005$ \\
& {$[-5.170 \mathrm{eV}]$} & {$[-3.236 \mathrm{eV}]$} & {$[-3.064 \mathrm{eV}]$} & \\
$\mathrm{DPV}$ & $+0.797 \pm 0.002$ & $-1.080 \pm 0.002$ & $-1.327 \pm 0.002$ & $1.877 \pm 0.002$ \\
& {$[-5.133 \mathrm{eV}]$} & {$[-3.256 \mathrm{eV}]$} & {$[-3.009 \mathrm{eV}]$} & \\
$\mathrm{CV}-$ Os-SAc & $+0.844 \pm 0.004 \mathrm{r}$ & - & & - \\
on Au & {$[-5.180 \mathrm{eV}]$} & & & \\
\hline
\end{tabular}

Notation: $r$ = reversible; ir $=$ irreversible

Os-SAc-SAMs on Au. The SAM was formed on a Au electrode, pre-cleaned with ethanol, by immersing the electrode in an acetonitrile solution of Os-SAc $\left(\sim 10^{-3} \mathrm{M}\right)$ for $24 \mathrm{~h}$. The electrode was later rinsed thoroughly with ethanol to remove any unbound molecule from the surface. The electrochemical characterization, performed in $\mathrm{CH}_{3} \mathrm{CN} / 0.1 \mathrm{M}$ TBAH by means of $\mathrm{CV}$ in the positive range, shows a reversible oxidation process, as displayed in Fig. 7. The scan rate has been varied from 0.1 up to $2 \mathrm{~V} \mathrm{~s}^{-1}$.

For the Os-SAc monolayer, the surface coverage was determined from the area under the voltammogram peak observed for the oxidation process, by using the following equation:

$$
\Gamma=\frac{Q}{n F A}
$$

where $Q$, is the total charge required to oxidize or reduce the electroactive species, $n$ is the number electrons involved in the electrochemical process, $F$ is the Faraday constant, and $A$ is the area of the electrode. The effective area of the electrode was measured by analyzing the $\mathrm{CVs}$ of ferrocene/ferricenium redox couple varying the scan rate in the range $0.1-1 \mathrm{~V} \mathrm{~s}^{-1}$, and was estimated to be $1.12 \times 10^{-2} \mathrm{~cm}^{2}$ with a roughness factor $\rho$ of 1.69 [71]. The resulting surface coverage was calculated from the area under the voltammetric peak as the scan rate is varied in the range $0.1-2 \mathrm{~V} \mathrm{~s}^{-1}$, and was found to be $4.64 \times 10^{-11} \mathrm{~mol} / \mathrm{cm}^{2}$. This value is about one order of magnitude smaller than those reported in literature for alkanethiol SAMs on $\mathrm{Au}(111)$ [72-74]. However, it is not surprising, since the steric hindrance 


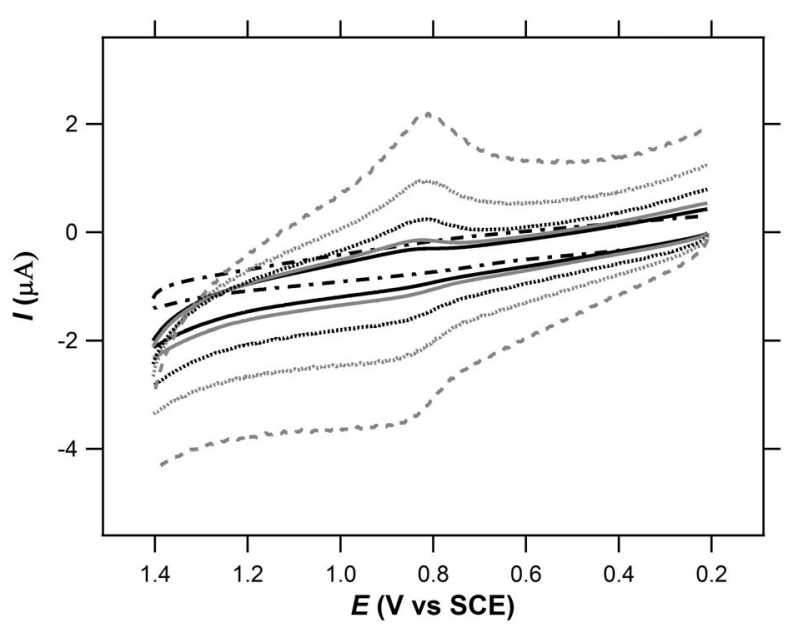

Fig. $7 \mathrm{CV}$ of Os-SAc-SAMs in $\mathrm{CH}_{3} \mathrm{CN} / 0.1 \mathrm{M}$ TBAH, particular of Os(III)/Os(II) redox process. Scan rate 0.1 (black), 0.2 (gray), 0.5 (black dotted), 1 (gray dotted), 2 (gray dashed) $\mathrm{V} \mathrm{s}^{-1}$ respectively. The $\mathrm{CV}$ for the bare Au electrode at $0.1 \mathrm{~V} \mathrm{~s}^{-1}$ is also reported (- - ). Working electrode: Au disk electrode; counter: Pt coil; reference: Pt QRE. Calibration vs SCE with $\mathrm{Fc}^{+} / \mathrm{Fc}$ as internal standard.

of the tripod is higher than that provided by alkane chains, and the roughness of the electrode surface is not comparable with that provided by crystalline $\mathrm{Au}(111)$.

It is interesting to note that the peak separation $E_{\mathrm{p}}$ is greater than 0 and slightly increases with increasing scan rates $(50 \mathrm{mV}$ at $1 \mathrm{~V} / \mathrm{s}$ as compared to $30 \mathrm{mV}$ at $100 \mathrm{mV} / \mathrm{s}$ ). This is consistent with similar trends observed for Os bipyridine complexes on Au surfaces [27]. Furthermore, the peak-current increases linearly with the scan rate, as expected for diffusion-less process due to species directly bound on the electrode surfaces [62].

\section{Tunneling junction with SAMs of Os-SAc}

We fabricated tunneling junctions of SAMs of Os-SAc on ultra-flat TS Au surface by contacting them with a liquid metal (eutectic alloy of In and Ga, EGaIn) top electrode. The method for forming coneshaped tips of $\mathrm{GaO}_{\mathrm{x}} / \mathrm{EGaIn}$ and to contact the SAMs to form tunneling junctions has been described before [47]. This method makes it possible to study the mechanism of charge transfer across SAMs as a function of the chemical composition of the SAMs with statistically large numbers of data [75]. These junctions are easy to assemble, are relatively mechanically stable, and the liquid-metal top electrode, unlike methods based on the direct deposition of metals [76], does not alter the chemical structure of the SAMs, or penetrate the SAM [77,78].

The tunneling junctions contain a surface layer of $\mathrm{Ga}$ oxide, $\mathrm{GaO}_{\mathrm{x}}$, which spontaneously forms on EGaIn under ambient conditions. We have characterized this surface layer of $\mathrm{GaO}_{\mathrm{x}}$ in three different ways. (i) The thickness of the layer of $\mathrm{GaO}_{\mathrm{x}}$ measured by time-of-flight-secondary ion mass spectrometry (TOF-SIMS) and angle-resolved X-ray photoelectron spectroscopy (XPS) is 1-2 nm. (ii) The resistivity of the layer of $\mathrm{GaO}_{\mathrm{x}}$ is about two orders of magnitude higher than that of bulk EGaIn, and about four orders of magnitude less than a SAM of $\mathrm{SC}_{10} \mathrm{CH}_{3}$, and is therefore negligible in our studies of charge transport across SAMs [75]. (iii) The surface of the $\mathrm{GaO}_{\mathrm{x}}$ is not smooth and the actual contact area of the $\mathrm{GaO}_{\mathrm{x}}$ with the SAM is $\sim 25 \%$ of that of the measured contact area. All tunneling junctions contain SAMs that have defects due to step edges, impurities, grain boundaries, etc. [6]. For this reason, statistically large numbers of data have to be recorded and analyzed to discriminate artifact from real data, and to determine the reproducibility and the yield of working devices [75,79]. Figure 8 shows 


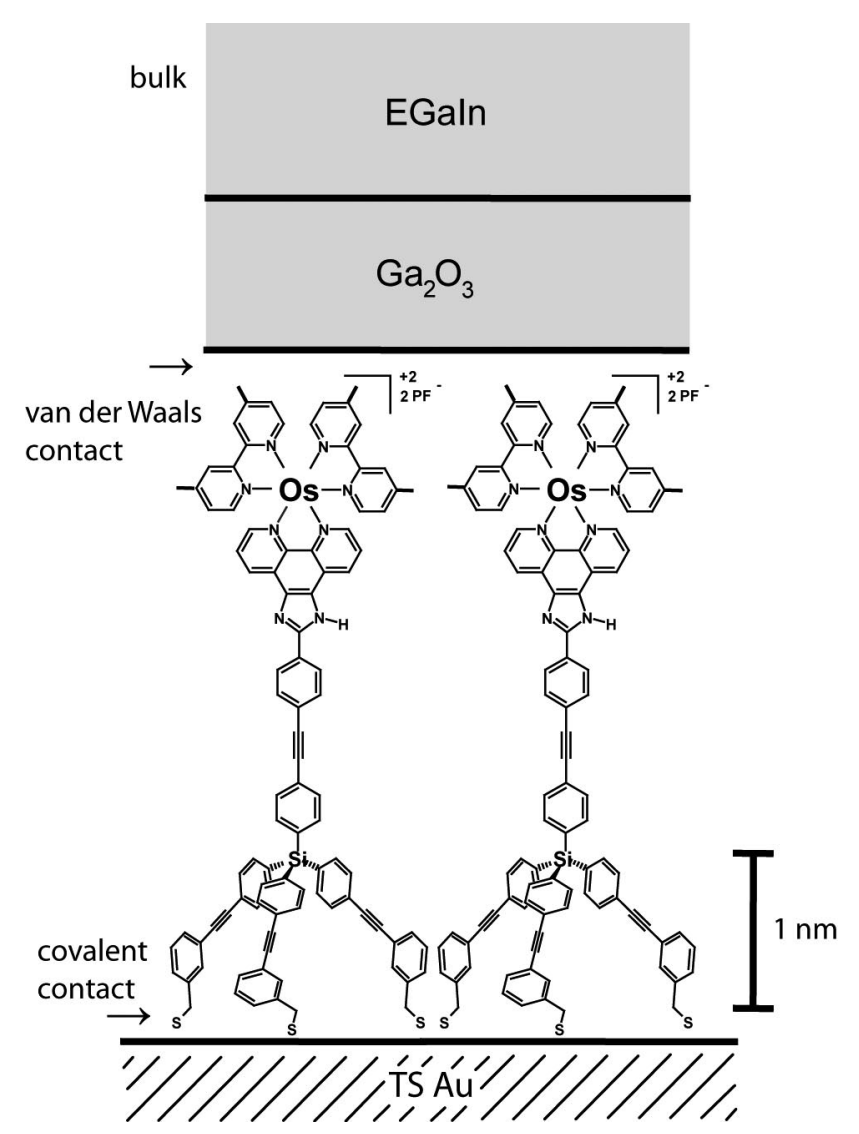

Fig. 8 Schematic representation of the TS Au-Os-tripod//GaO $/ \mathrm{EGaIn}_{\mathrm{E}}$ tunnel junction. The $\mathrm{GaO}_{\mathrm{x}} / \mathrm{EGaIn}$ top electrode is biased, and the TS Au bottom electrode is grounded.

the tunneling junction schematically. In all experiments, we biased the $\mathrm{GaO}_{\mathrm{x}} / \mathrm{EGaIn}$ top electrode and grounded the $\mathrm{Au}^{\mathrm{TS}}$ electrode and the junction sizes were $500-1000 \mu \mathrm{m}^{2}$.

A total of 11 junctions were assembled at 2 different TS Au surfaces. All of these junctions were working and no junctions were shorting, thus the yield of working devices was $100 \%$. The junctions were then scanned between -2 and $+2 \mathrm{~V}$. We performed a statistical analysis of the data by a procedure reported earlier [75]. The semi-log plot of the average $|J|(\mathrm{V})$-curve is shown in Fig. 9. The junctions exhibited rectification with a rectification ratio $R=32$ with a log-standard deviation of 1.5 measured at $\pm 2.0 \mathrm{~V}$ (see supplementary information), with $R$ given by the following equation where $J$ is the current density $\left(\mathrm{A} / \mathrm{cm}^{2}\right), V$ is the voltage $(\mathrm{V})$.

$$
R=|J(-\mathrm{V})| /|J(\mathrm{~V})|
$$



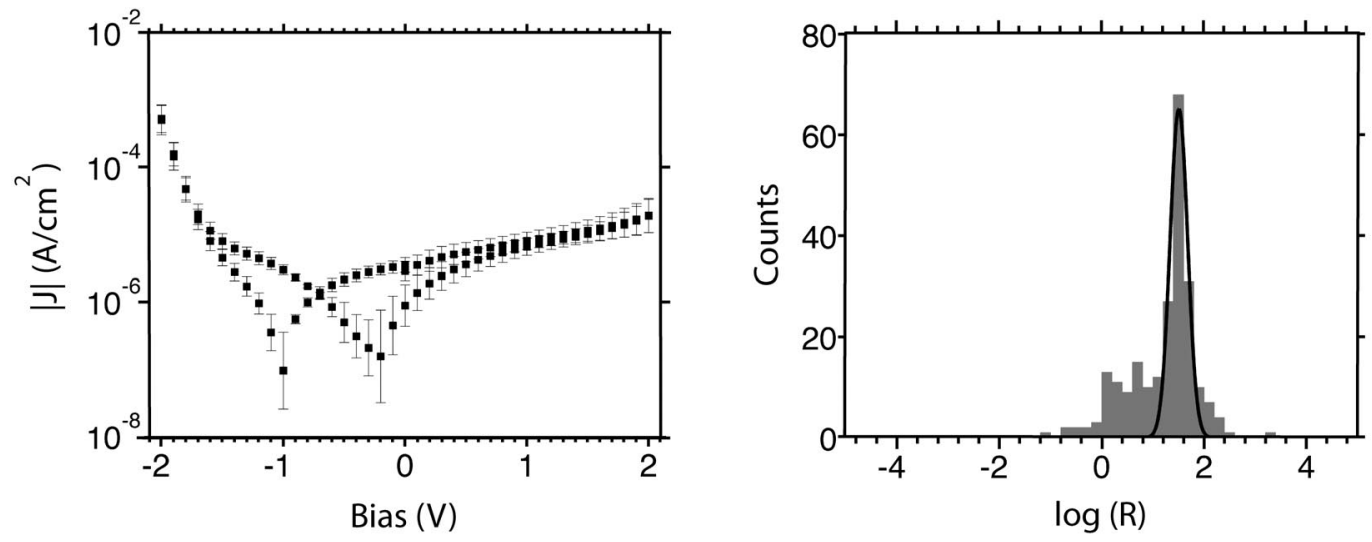

Fig. 9 (left) The average $|J|(\mathrm{V})$ semi log-plot of the TS Au-Os//EGaIn junctions $(\bullet)$ and the corresponding error bars. One trace $=0 \mathrm{~V} \rightarrow+2.0 \mathrm{~V} \rightarrow 2.0 \mathrm{~V} \rightarrow 0 \mathrm{~V}$. (right) Histogram of the rectification ratios (R) with a Gaussian fit.

We reported that junctions with SAMs of Ru-tripod on TS Au bottom electrodes and $\mathrm{GaO}_{\mathrm{x}}$ top electrode have energetically accessible HOMO and LUMO levels which may overlap with the Fermi levels of the electrodes in the measured bias window $( \pm 2.0 \mathrm{~V})$, but these junctions did not rectify currents significantly $(R \approx 1.0)$ [24]. In contrast, the junctions with SAMs of Os-tripod rectified. As outlined in Fig. 10, both tripod molecules have LUMO levels of $-3.1 \mathrm{eV}$, but the HOMO level of the Os-tripod $(-5.2 \mathrm{eV})$ is $0.60 \mathrm{eV}$ higher in energy than that of the Ru-tripod $(-5.8 \mathrm{eV})$. Although the HOMO and LUMO levels will be delocalized, we believe that both levels will be located spatially asymmetrically inside the junction, and that they will be in close proximity with the top electrode. Thus, the HOMO and LUMO levels will follow the Fermi level of the $\mathrm{GaO}_{\mathrm{x}}$ top electrode when bias is applied. We do not know how closely the HOMO and LUMO levels will follow the Fermi level of the $\mathrm{GaO}_{\mathrm{x}}$
$\mathrm{V}=2 \mathrm{~V}$
$\mathrm{V}=\mathrm{OV}$
$V=-2 V$

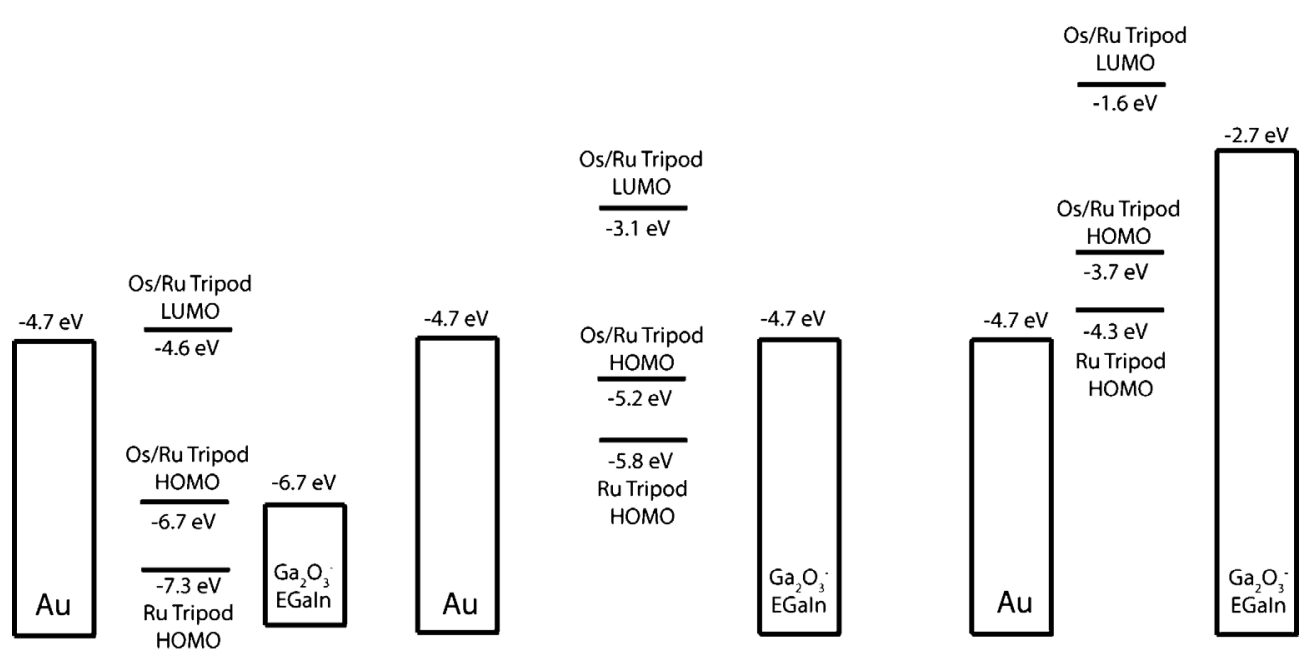

Fig. 10 The proposed energy level diagrams for junctions of SAMs of Os- and Ru-tripod on Au bottom electrodes and $\mathrm{GaO}_{\mathrm{x}} / \mathrm{EGaIn}$ electrodes at a bias $V=2.0 \mathrm{~V}$ (left), $V=0 \mathrm{~V}$ (middle), and $V=-2.0 \mathrm{~V}$ (left). 
electrode, but in Fig. 10 we assumed that at a bias of $2.0 \mathrm{~V}$ the HOMO and LUMO levels shift $1.5 \mathrm{eV}$ in energy.

In case of the Ru-tripod [24], the Fermi level of the $\mathrm{GaO}_{\mathrm{x}}$ top electrode $(-4.3 \mathrm{eV})$ is located energetically close to the middle of the HOMO-LUMO gap. In contrast, in case of the Os-tripod, the Fermi level of the $\mathrm{GaO}_{\mathrm{x}}$ top electrode is located energetically closer to the HOMO level than to the LUMO level. We believe that the rectification for the Os-SAc complex originates from the fact that at negative bias the HOMO level can overlap with the Fermi levels of both electrodes at lower applied potentials than at positive bias, and, consequently, facilitate charge transport in one direction of bias at lower applied potential than the other. Hence, rectification is achieved. In case of the Ru-tripod, however, the HOMO level probably does not overlap with the Fermi levels of both electrodes at any applied potential. Thus, despite the fact that the HOMO level is spatially located inside the junction asymmetrically, rectification cannot be achieved. We propose a mechanism of rectification that involves one molecular orbital similar to that proposed by the groups of Baranger et al. [80] and Kornilovitch et al. [81]. They proposed that an asymmetrically positioned molecular orbital, (either HOMO or LUMO) inside a tunneling junction and strongly coupled to one of the electrodes, can rectify current. Most likely, the LUMO level does not overlap with the Fermi level of the electrodes under the applied bias window, since the LUMO level is about $1.4 \mathrm{eV}$ lower in energy than the Fermi levels of the electrodes.

\section{CONCLUSIONS}

Redox-active electroluminescent $d^{6}$ Os(II) and Ir(III) metal complexes with rigid geometries for molecular electronics application, have been prepared. They contain a phenanthroline ligand substituted with a tripod system that terminates with thiol functionalities. A detailed photophysical characterization of these complexes has been reported. Furthermore, we have investigated SAMs of Os(II) complexes on ultraflat Au surfaces and characterized them by AFM. We have also fabricated a metal-molecule-metal junction with these tripodal complexes using a eutectic of $\mathrm{Ga}-\mathrm{In}$ alloy as a top electrode and $\mathrm{Au}$ as the bottom electrode. We report a rectification behavior in these junctions. However, the directionality of the rectification is opposite to what we have described for $\mathrm{Ru}(\mathrm{II})$-tripods in our previous study.

\section{SUPPLEMENTARY INFORMATION}

Supplementary information is available online (doi:10.1351/PAC-CON-10-11-07).

\section{ACKNOWLEDGMENT}

Funding from NanoNed, which is an initiative from Dutch ministry of economic affairs, project number AMM7010 is acknowledged.

\section{REFERENCES}

1. C. A. Mirkin, M. A. Ratner. Annu. Rev. Phys. Chem. 43, 719 (1992).

2. C. Joachim, J. K. Gimzewski, A. Aviram. Nature 408, 541 (2000).

3. F. Chen, J. Hihath, Z. Huang, X. Li, N. J. Tao. Annu. Rev. Phys. Chem. 58, 535 (2007).

4. W. R. Dichtel, J. R. Heath, J. Fraser Stoddart. Philos. Trans. R. Soc. A 365, 1607 (2007).

5. T. Y. Dong, C. L. Huang, C. P. Chen, M. C. Lin. J. Organomet. Chem. 692, 5147 (2007).

6. J. C. Love, L. A. Estroff, J. K. Kriebel, R. G. Nuzzo, G. M. Whitesides. Chem. Rev. 105, 1103 (2005).

7. A. Ulman. Chem. Rev. 96, 1533 (1996).

8. J. M. Mativetsky, G. Pace, M. Elbing, M. A. Rampi, M. Mayor, P. Samori. J. Am. Chem. Soc. 130, 9192 (2008). 
9. J. Reichert, R. Ochs, D. Beckmann, H. B. Weber, M. Mayor, H. v. Löhneysen. Phys. Rev. Lett. 88, 176804 (2002).

10. N. Weibel, A. Mishchenko, T. Wandlowski, M. Neuburger, Y. Leroux, M. Mayor. Eur. J. Org. Chem. 6140 (2009).

11. S. Wu, M. T. Gonzalez, R. Huber, S. Grunder, M. Mayor, C. Schonenberger, M. Calame. Nat. Nano. 3, 569 (2008).

12. N. Tuccitto, V. Ferri, M. Cavazzini, S. Quici, G. Zhavnerko, A. Licciardello, M. A. Rampi. Nat. Mater. 8, 41 (2009).

13. E. Tran, A. E. Cohen, R. W. Murray, M. A. Rampi, G. M. Whitesides. J. Am. Chem. Soc. 131, 2141 (2009).

14. S. Ballmann, W. Hieringer, D. Secker, Q. Zheng, J. A. Gladysz, A. Görling, H. B. Weber. ChemPhysChem 11, 2256 (2010).

15. D. Secker, H. B. Weber. Phys. Status Solidi B 244, 4176 (2007).

16. J. S. Seldenthuis, H. S. J. van der Zant, M. A. Ratner, J. M. Thijssen. Phys. Rev. B 81, 205430 (2010).

17. G. E. Poirier, E. D. Pylant. Science 272, 1145 (1996).

18. M. D. Porter, T. B. Bright, D. L. Allara, C. E. D. Chidsey. J. Am. Chem. Soc. 109, 3559 (1987).

19. C. D. Bain, J. Evall, G. M. Whitesides. J. Am. Chem. Soc. 111, 7155 (1989).

20. P. E. Laibinis, G. M. Whitesides, D. L. Allara, Y. T. Tao, A. N. Parikh, R. G. Nuzzo. J. Am. Chem. Soc. 113, 7152 (1991).

21. E. Figgemeier, E. C. Constable, C. E. Housecroft, Y. C. Zimmermann. Langmuir 20, 9242 (2004).

22. K. Terada, K. Kobayashi, M.-a. Haga. Dalton Trans. 4846 (2008).

23. A. D'Aleo, R. M. Williams, Y. Chriqui, Vijay M. Iyer, P. Belser, F. Vergeer, V. Ruiz, P. R. Unwin, L. De Cola. Open Inorg. Chem. J. 1, 26 (2007).

24. S. Ramachandra, K. C. Schuermann, F. Edafe, P. Belser, C. A. Nijhuis, W. F. Reus, G. M. Whitesides, L. De Cola. Inorg. Chem. 50, 1581 (2011).

25. R. J. Forster, E. Figgemeier, A. C. Lees, J. Hjelm, J. G. Vos. Langmuir 16, 7867 (2000).

26. R. J. Forster, E. Figgemeier, P. Loughman, A. Lees, J. Hjelm, J. G. Vos. Langmuir 16, 7871 (2000).

27. A. Ricci, C. Rolli, S. Rothacher, L. Baraldo, C. Bonazzola, E. Calvo, N. Tognalli, A. Fainstein. J. Solid State Electrochem. 11, 1511 (2007).

28. J. E. Hudson, H. D. Abruna. J. Phys. Chem. 100, 1036 (1996).

29. J. D. Tirado, H. D. Abruna. J. Phys. Chem. 100, 4556 (1996).

30. J. D. Tirado, D. Acevedo, R. L. Bretz, H. D. Abruna. Langmuir 10, 1971 (1994).

31. D. Acevedo, H. D. Abruna. J. Phys. Chem. 95, 9590 (1991).

32. T. Albrecht, K. Moth-Poulsen, J. B. Christensen, A. Guckian, T. Bjornholm, J. G. Vos, J. Ulstrup. Faraday Discuss. 131, 265 (2006).

33. N. M. O’Boyle, T. Albrecht, D. H. Murgida, L. Cassidy, J. Ulstrup, J. G. Vos. Inorg. Chem. 46, 117 (2006).

34. T. Kitagawa, Y. Idomoto, H. Matsubara, D. Hobara, T. Kakiuchi, T. Okazaki, K. Komatsu. J. Org. Chem. 71, 1362 (2006).

35. M. A. Fox, J. K. Whitesell, A. J. McKerrow. Langmuir 14, 816 (1998).

36. J. S. Park, A. N. Vo, D. Barriet, Y. S. Shon, T. R. Lee. Langmuir 21, 2902 (2005).

37. E. Galoppini, W. Guo, W. Zhang, P. G. Hoertz, P. Qu, G. J. Meyer. J. Am. Chem. Soc. 124, 7801 (2002).

38. T. Weidner, A. Kramer, C. Bruhn, M. Zharnikov, A. Shaporenko, U. Siemeling, F. Trager. Dalton Trans. 2767 (2006).

39. H. Jian, J. M. Tour. J. Org. Chem. 68, 5091 (2003).

40. M. S. Lowry, W. R. Hudson, R. A. Pascal, S. Bernhard. J. Am. Chem. Soc. 126, 14129 (2004). 
41. K. Kalyanasundaram. In Photochemistry of Polypyridine and Porphyrin Complexes, Academic Press, New York (1972).

42. Y. Nakabayashi, K. Nakamura, M. Kawachi, T. Motoyama, O. Yamauchi. J. Biol. Inorg. Chem. 8, 45 (2003).

43. M. Yamada, Y. Tanaka, Y. Yoshimoto, S. Kuroda, I. Shimao. Bull. Chem. Soc. Jpn. 65, 1006 (1992).

44. E. M. Kober, J. V. Caspar, R. S. Lumpkin, T. J. Meyer. J. Phys. Chem. 90, 3722 (1986).

45. E. A. Weiss, R. C. Chiechi, G. K. Kaufman, J. K. Kriebel, Z. Li, M. Duati, M. A. Rampi, G. M. Whitesides. J. Am. Chem. Soc. 129, 4336 (2007).

46. E. A. Weiss, G. K. Kaufman, J. K. Kriebel, Z. Li, R. Schalek, G. M. Whitesides. Langmuir 23, 9686 (2007).

47. R. C. Chiechi, E. A. Weiss, M. D. Dickey, G. M. Whitesides. Angew. Chem., Int. Ed. 47, 142 (2008).

48. W. Y. Huang, W. Gao, T. K. Kwei, Y. Okamoto. Macromolecules 34, 1570 (2001).

49. K. Kalyanasundaram. In Photophysics and Photochemistry of Polypyridyl and Porphyrin Complexes, p. 626, Academic Press, New York (1992).

50. D. Kumaresan, K. Shankar, S. Vaidya, R. Schmehl. In Photochemistry and Photophysics of Coordination Compounds II, Series Topics in Current Chemistry, Vol. 281, V. Balzani, S. Campagna (Eds.), pp. 101-142 (2007).

51. S. Verma, P. Kar, Amitava Das, D. K. Palit, H. N. Ghosh. Chem.-Eur. J. 16, 611 (2010).

52. P. Kar, S. Verma, A. Das, H. N. Ghosh. J. Phys. Chem. C 113, 7970 (2009).

53. H. Yersin, C. Kratzer. Coord. Chem. Rev. 229, 75 (2002).

54. L. Flamigni, A. Barbieri, C. Sabatini, B. Ventura, F. Barigelletti. Top. Curr. Chem. 281, 143 (2007).

55. F. O. Garces, K. A. King, R. J. Watts. Inorg. Chem. 27, 3464 (1988).

56. K. Ichimura, T. Kobayashi, K. A. King, R. J. Watts. J. Phys. Chem. 91, 6104 (2002).

57. F. Lafolet, S. Welter, Z. Popovic, L. De Cola. J. Mater. Chem. 15, 2820 (2005).

58. A. Juris, S. Campagna, I. Bidd, J. M. Lehn, R. Ziessel. Inorg. Chem. 27, 4007 (1988).

59. P. Pramod, P. K. Sudeep, K. G. Thomas, P. V. Kamat. J. Phys. Chem. B 110, 20737 (2006).

60. P. Bertoncello, E. T. Kefalas, Z. Pikramenou, P. R. Unwin, R. J. Forster. J. Phys. Chem. B 110, 10063 (2006).

61. A. D'Aleo, R. M. Williams, Y. Chriqui, Vijay M. Iyer, P. Belser, F. Vergeer, V. Ruiz, P. R. Unwin, L. De Cola. Open Inorg. Chem. J. 1, 26 (2007).

62. C. E. D. Chidsey. Science 251, 919 (1991).

63. H. O. Finklea, D. D. Hanshew. J. Am. Chem. Soc. 114, 3173 (1992).

64. D. P. Rillema, G. Allen, T. J. Meyer, D. C. Conrad. Inorg. Chem. 22, 1617 (1983).

65. E. Amouyal, A. Homsi, J.-C. Chambron, J.-P. Sauvage. J. Chem. Soc., Dalton Trans. 1841 (1990).

66. F. Barigelletti, A. Juris, V. Balzani, P. Belser, A. v. Zelewsky. Inorg. Chem. 27, 4115 (1987).

67. J.-Z. Wu, B.-H. Ye, L. Wang, L.-N. Ji, J.-Y. Zhou, R.-H. Li, Z.-Y. Zhou. J. Chem. Soc., Dalton Trans. 1395 (1997).

68. L.-F. Tan, S. Zhang, H. Chao, K.-C. Zheng, F. Wang, Y. Xiao, L.-N. Ji. Helv. Chim. Acta 90, 1786 (2007).

69. K. Omer, S. Y. Ku, K. T. Wong, A. Bard. Angew. Chem., Int. Ed. 48, 9300 (2009).

70. M. Thelakkat, H.-W. Schmidt. Adv. Mater. 10, 219 (1998).

71. A. J. Bard, L. R. Faulkner. Electrochemical Methods, Fundamentals and Applications, John Wiley, New York (2001).

72. L. Strong, G. M. Whitesides. Langmuir 4, 546 (1988).

73. D. M. Collard, M. A. Fox. Langmuir 7, 1192 (1991).

74. D. Hobara, M. Ota, S.-i. Imabayashi, K. Niki, T. Kakiuchi. J. Electroanal. Chem. 444, 113 (1998).

75. C. A. Nijhuis, W. F. Reus, G. M. Whitesides. J. Am. Chem. Soc. 131, 17814 (2009). 
76. A. V. Walker, T. B. Tighe, O. M. Cabarcos, M. D. Reinard, B. C. Haynie, S. Uppili, N. Winograd, D. L. Allara. J. Am. Chem. Soc. 126, 3954 (2004).

77. J. M. Beebe, J. G. Kushmerick. Appl. Phys. Lett. 90, 083117 (2007).

78. C. N. Lau, D. R. Stewart, R. S. Williams, M. Bockrath. Nano Lett. 4, 569 (2004).

79. T. W. Kim, G. Wang, H. Lee, T. Lee. Nanotechnology 18, 315204 (2007).

80. R. Liu, S.-H. Ke, W. Yang, H. U. Baranger. J. Chem. Phys. 124, 024718 (2006).

81. P. E. Kornilovitch, A. M. Bratkovsky, R. S. Williams. Phys. Rev. B 66, 165436 (2002). 